\title{
From thin to extra-thick adhesive layer thicknesses: Fracture of bonded joints under mode I loading conditions
}

\author{
Romina Lopes Fernandes ${ }^{\mathrm{a}, *}$, Sofia Teixeira de Freitas ${ }^{\mathrm{a}}$, Michal K. Budzik ${ }^{\mathrm{b}}$, \\ Johannes A. Poulis ${ }^{\mathrm{a}}$, Rinze Benedictus ${ }^{\mathrm{a}}$ \\ ${ }^{a}$ Structural Integrity \& Composites Group, Faculty of Aerospace Engineering, Delft University of Technology, P.O. Box 5058, 2600 GB Delft, The \\ Netherlands \\ ${ }^{\mathrm{b}}$ Department of Engineering, Aarhus University, Inge Lehmanns Gade 10, 8000 Aarhus C, Denmark
}

\section{A R T I C L E I N F O}

\section{Keywords:}

Mode I

Fracture toughness

Extra-thick bond lines

Fracture process zone

\begin{abstract}
A B S T R A C T
The fracture behaviour of joints bonded with a structural epoxy adhesive and bond line thicknesses of 0.1-4.5 mm has been studied. However, limited research is found on similar joints with thicker bond lines, which are relevant for maritime applications. Therefore, the effect of the adhesive bond line thickness, varying from 0.4 to $10.1 \mathrm{~mm}$, on the mode I fracture behaviour of steel to steel joints bonded with a structural epoxy adhesive was investigated in this study. An experimental test campaign of double-cantilever beam (DCB) specimens was carried out in laboratory conditions. Five bond line thicknesses were studied: $0.4,1.1,2.6,4.1$ and $10.1 \mathrm{~mm}$. Analytical predictions of the experimental load-displacement curves were performed based on the Simple Beam Theory (SBT), the Compliance Calibration Method (CCM) and the PenadoKanninen (P-K) model. The P-K model was used to determine the mode I strain energy release rate (SERR). The average mode I SERR, $G_{\mathrm{I}}$ av., presented similar values for the specimens with adhesive bond line thicknesses of $0.4,1.1$ and $2.6 \mathrm{~mm}\left(G_{\text {I av }}=0.71,0.61,0.63 \mathrm{~N} / \mathrm{mm}\right.$, respectively). However, it increased by approximately $63 \%$ for $4.1 \mathrm{~mm}\left(G_{\mathrm{I} \text { av. }}=1.16 \mathrm{~N} / \mathrm{mm}\right)$ and decreased by about $10 \%$ (in comparison with $4.1 \mathrm{~mm})$ for the $10.1 \mathrm{~mm}\left(G_{\text {I av. }}=1.04 \mathrm{~N} / \mathrm{mm}\right)$. The trend of the $G_{\mathrm{I}}$ av. in relation to the bond line thickness is explained by the combination of three factors: the crack path location, the failure surfaces features and the stress field ahead of the crack tip.
\end{abstract}

\section{Introduction}

In the shipbuilding industry, there is a growing demand for total weight reduction. Lighter ships can carry higher loads, improving the efficiency of the services, such as cargo transport. Towards this aim, traditionally steel-made components are being replaced by composite materials. This results in bi-material adhesively bonded steel-composite structures. Moreover, the efficient production of large shipbuilding structures leads to bond line thicknesses up to $10 \mathrm{~mm}$. During the service life, the bonded regions are subjected to multiaxial loading, which can be decomposed to simple peel and shear stresses. In the present study, the effect of the peel stresses on those extra-thick bond lines $(10 \mathrm{~mm})$ is investigated by means of fracture tests under mode I loading conditions.

Research on the effect of the adhesive bond line thickness on mode I fracture behaviour has mainly focused either on joints bonded with structural epoxy adhesives with bond line thicknesses normally ranging between 0.1 and $2 \mathrm{~mm}-$ mostly applied to

\footnotetext{
* Corresponding author.

E-mail address: R.LopesFernandes@tudelft.nl (R. Lopes Fernandes).
} 


\section{Nomenclature}

Latin symbols

a specimen crack length ( $\mathrm{mm}$ )

$a_{\mathrm{SBT}} \quad$ estimated crack length based on Simple Beam

Theory (mm)

$a_{0} \quad$ specimen pre-crack length (mm)

$B \quad$ specimen width (mm)

C specimen compliance $(\mathrm{mm} / \mathrm{N})$

$E$ tensile modulus of isotropic material $\left(\mathrm{N} / \mathrm{mm}^{2}\right)$

$E_{\text {a }} \quad$ Young's modulus of adhesive $\left(\mathrm{N} / \mathrm{mm}^{2}\right)$

$G_{\mathrm{I}} \quad$ mode I strain energy release rate $(\mathrm{N} / \mathrm{mm})$

$G_{\text {I av. }} \quad$ average mode I strain energy release rate $(\mathrm{N} / \mathrm{mm})$

$G_{\text {Ic }} \quad$ critical mode I fracture energy of a bonded joint $(\mathrm{N} / \mathrm{mm})$

$G_{\text {Ic-a }} \quad$ critical mode I fracture energy of bulk adhesive $(\mathrm{N} / \mathrm{mm})$

$G_{\text {I-CCM }}$ strain energy release rate based on Compliance Calibration Method (N/mm)

$G_{\text {I-P-K }}$ strain energy release rate based on PenadoKanninen model $(\mathrm{N} / \mathrm{mm})$

$G_{\text {I-SBT }} \quad$ strain energy release rate based on Simple Beam Theory $(\mathrm{N} / \mathrm{mm})$

$h \quad$ adherend thickness ( $\mathrm{mm}$ )

I second moment of the beam cross-section area $\left(\mathrm{mm}^{4}\right)$

$k$ foundation modulus $\left(\mathrm{N} / \mathrm{mm}^{2}\right)$

$L \quad$ specimen length (mm)

$m_{\mathrm{q}} \quad$ constant to define stress state at the crack front (-)

$m_{1} \quad$ 3D plane stress state (-)

$m_{2} \quad$ 2D plane strain state $(-)$

$m_{3} \quad$ 3D plane strain state $(-)$

$n \quad$ slope of $\log -\log$ plot of $\Omega$ versus $a(-)$

$P \quad$ applied load (N)

$P_{\mathrm{CCM}} \quad$ Compliance Calibration Method estimated applied load $(\mathrm{N})$

$P_{\max } \quad$ maximum applied load (N)

$r_{\mathrm{p}} \quad$ radius of fracture process zone $(\mathrm{mm})$

$S_{\mathrm{a}} \quad$ average areal roughness $(\mu \mathrm{m})$

$S_{\mathrm{q}} \quad$ root mean square deviation $(\mu \mathrm{m})$

$t \quad$ half of adhesive bond line thickness (mm)

$w \quad$ displacement of Penado-Kanninen model (mm)

$w_{\text {bon }} \quad$ displacement of Penado-Kanninen model in the bonded region $(-\infty \leqslant x \leqslant 0)(\mathrm{mm})$

displacement of Penado-Kanninen model in the unbonded region $(0 \leqslant x \leqslant a)(\mathrm{mm})$

Greek symbols

$\begin{array}{ll}\beta & \left(\frac{B G_{\mathrm{Ic}}}{n}\right)^{\frac{n}{n+1}} \cdot\left(\frac{2}{\chi}\right)^{\frac{1}{n+1}}(-) \\ \Delta & \text { half-specimen displacement (mm) } \\ \lambda & \text { wave number }\left(\mathrm{mm}^{-1}\right) \\ \lambda^{-1} & \text { elastic process zone length (mm) } \\ \lambda_{j-\exp }^{-1} & \text { experimental elastic process zone length } \\ & (j=0.4,1.1,2.6,4.1,10.1)(\mathrm{mm}) \\ \nu & \text { Poisson's ratio of isotropic material (-) } \\ \nu_{\mathrm{a}} & \text { Poisson's ratio of the adhesive (-) } \\ \sigma_{\text {yield }} & \text { yield strength }\left(\mathrm{N} / \mathrm{mm}^{2}\right) \\ \sigma_{z z} & \text { peel stress in } z \text {-direction }\left(\mathrm{N} / \mathrm{mm}^{2}\right) \\ \chi & \text { Compliance Calibration Method curve fitting } \\ & \text { parameter }(-) \\ \psi & \frac{B}{3} \sqrt[4]{\frac{3 E h^{3}}{4}} G_{\mathrm{Ic}}^{3 / 4}\left(\mathrm{~N} . \mathrm{mm} \frac{1}{2}\right) \\ \Omega & \chi^{-1} \cdot a^{-n}(\mathrm{~N} / \mathrm{mm})\end{array}$

Acronyms

ASTM American Society for Testing and Materials

CCM Compliance Calibration Method

DCB Double-Cantilever Beam

DOI Digital Object Identifier

DW Distilled Water

GPS glycidoxypropyltrimethoxysilane

HTSM HighTech Systemen \& Materialen

ISO International Organization for Standardization

JIP Joint Industry Project

LED Light Emitting Diode

M2i Materials Innovation Institute

$\mathrm{pH} \quad$ potential of Hydrogen

P-K Penado-Kanninen

rpm revolutions per minute

SBT Simple Beam Theory

SERR Strain Energy Release Rate

TKI Topconsortium voor Kennis en Innovatie

TNO Netherlands Organisation for Applied Scientific Research

TTW Technology Foundation

aerospace and automotive applications [1-13], or on joints with flexible adhesives often with thicker bond lines [14,4,15,16]. However, limited studies were found on joints with extra-thick bond lines $(\approx 10 \mathrm{~mm})$ of epoxy adhesives, relevant for maritime applications. The research done in the past has proved that there is a dependence of the fracture energy of adhesive joints on bonding thickness, regardless of the nature of the adhesives. However, there is no single trend for this dependency.

Structural adhesives, such as epoxy adhesives, possess elasto-plastic yield performance. When these toughened adhesives are applied in bonded joints, there are two mechanisms governing the bond line thickness dependence of the mode I fracture energy of the joint (assuming good adhesion at the adherend-adhesive interface): the stress field at the crack tip and the consequent plastic deformation zone. The plastic deformation zone develops ahead of the crack tip in consequence of multiple micro-cracks nucleation through the adhesive thickness and plastification. In a bulk adhesive specimen, when tensile loaded, is assumed that this zone has a circular shape of diameter equal to $2 r_{\mathrm{p}}$, where $r_{\mathrm{p}}$ is Irwin's first order estimate of the plastic zone size (more details about $2 r_{\mathrm{p}}$ estimation are given in Section 5). In a bonded joint, the physical constraints of the adherends affect the stress field at the crack tip and, consequently, the shape and size of the plastic deformation zone. The influence of the adherends on the geometry of the plastic zone varies with the bond line thickness $[17,18]$.

In a bonded joint with a thin adhesive layer, the role of the interphases becomes dominant on the fracture behaviour of the joint. The term interphase relates to the adhesive volume adjacent to the surface of the adherend, which is assumed to possess properties 
different from those of the adhesive when cured in the absence of an adherend. It has been reported that epoxide based adhesives form interphases with an extension of up to $100 \mu \mathrm{m}$ from the adherends surfaces [19,20]. Geiss et al. [19] experimentally measured the local deformation of the adhesive layer and its interphases in shear-loaded bonded joints. The results showed that, in the elastic regime, the properties of the interphases were similar to those in the center of the adhesive joint. Nevertheless, the interphases revealed to be more sensitive to strain-induced softening, which was triggered once the polymer's yield point was exceeded. The study of the effect of the interphase on mode I fracture behaviour is distinct from the core objective of this paper and, consequently, it is not addressed.

Bascom et al. [3] investigated the effect of bond thickness on mode I fracture behaviour of aluminium with an epoxy adhesive and also investigated the toughening effects of adding elastomer particles to the epoxy adhesive (i.e., 15\% of the weight of the epoxy adhesive). The toughness of the joints with the unmodified epoxy was not affected by the bond line thickness in the studied range (i.e., from $0.25 \mathrm{~mm}$ up to $2 \mathrm{~mm}$ ). A sharp increase of almost 30 times was observed in the fracture toughness of the joints bonded with the elastomer-modified epoxy. Moreover, the fracture toughness of these joints was found to be strongly dependent upon the thickness of the adhesive layer. The fracture energy was maximized when the bond line thickness was about the size of the plastic zone formed at the crack tip (i.e., bond line thickness of $0.25-0.5 \mathrm{~mm}$ ). The maximum fracture energy was higher than the toughness of the bulk adhesive. As the bond line thickness was reduced below this maximum, the fracture energy of the bonded joints decreased due to restraint in the development of the plastic deformation zone (i.e., the thinner the bond, the smaller the volume of adhesive available to accommodate strain energy by deformation). Wang et al. [21] numerically predicted the stresses in the near field of the crack tip in bonded joints as a function of adherends/adhesive modulus ratio and adhesive thickness. The results showed that when the bond line thickness decreased, a shoulder developed on the local tensile stress distribution with the result that higher stresses extended along a larger distance ahead of the crack tip. This distance increased as the bond line thickness was decreasing.

The work of Kinloch and Shaw [6] supported the findings of Bascom et al. [3], however via a slightly modified argument based on the work of Wang et al. [21]. By assuming a stress singularity at the crack tip, Kinloch and Shaw supposed that the yield strength of the adhesive would be overreached in some zone ahead of the crack tip. Due to the fact that higher stresses spread out along a larger distance ahead of the crack tip as the bond line thickness decreased (as reported by Wang et al. [21]), Kinloch and Shaw assumed that the yield criterion would be exceeded at further distances from the crack tip. Consequently, this would result in more elongated plastic deformation zones. Their theory suggested that there is, in fact, a peak in the toughness of an adhesive joint when the adhesive bond line thickness approaches the diameter of the plastic deformation zone of a growing crack in a bulk adhesive specimen. In this case, the height of the plastic zone is, therefore, as predicted from the bulk adhesive specimen but its length ahead of the crack tip may be greater due to constraint from the adherends (at this bond line thickness, the adherends should offer enough constraint to enhance the plastic zone but not enough to restrict its development). Consequently, the volume of the plastic deformation zone should be larger in the adhesive joint than its volume in bulk adhesive specimens (i.e., the unconstrained state). As the toughness is mainly derived from the energy dissipated in forming the plastic zone, the maximum value is then observed in this case. Moreover, the fracture toughness of adhesive joints decreases at bond lines thinner than the bulk adhesive plastic zone diameter. Although the presence of stiff adherends extends the plastic zone length, the volume of the plastic zone is always smaller due to thinner bond lines. On the other hand, in joints with bond line thicknesses greater than the bulk adhesive plastic zone diameter, the constraint level from the adherends is lower, resulting in a reduction of the length of the plastic zone, and, thus, in lower values of the fracture energy of the joints. In this case, the toughness of the joints tends towards the toughness of the bulk adhesive.

The results of other researchers further supported the proposals of Bascom et al. [3] and Kinloch and Shaw [6] regarding the role of the plastic zone size on the fracture energy-bond line thickness relation of bonded joints. Hunston et al. [1] conducted fracture experiments on bonded joints composed by aluminium adherends and an elastomer-modified epoxy adhesive. Bonded joints with adhesive thicknesses of $0.38,1$ and $2 \mathrm{~mm}$ were tested and the stress-whitening that occurred at the crack tip was used to evaluate the size and shape of the plastic deformation zone. The results showed that the plastic deformation zone changes with the bond line thickness due to the physical constraint of the adherends and the stress field at the crack tip. The maximum value of the mode I fracture toughness was found to occur at a specific thickness where the height of the plastic deformation zone was equal to the bond line thickness. Maloney [4] investigated the mode I fracture behaviour of aluminium joints bonded with a structural epoxy adhesive Araldite 2015, with bond line thicknesses ranging from $0.2 \mathrm{~mm}$ to $4.0 \mathrm{~mm}$. Failure of the joints was observed to occur by cohesive propagation of a single crack. Evidence of plastic damage mechanisms occurring at the tip of the growing crack was found along the failure surface, such as stress whitening. The mode I fracture toughness of joints with bond line thicknesses of 0.2 and $0.3 \mathrm{~mm}$ was found to be much lower than the toughness of the bulk adhesive specimens, while the toughness of the $4.0 \mathrm{~mm}$ thick bond line joints was similar to the toughness of the bulk adhesive specimens. The joints with a finite adhesive bond line thickness of $1 \mathrm{~mm}$ were the toughest ones, even tougher than the bulk adhesive specimens. This maximum occurred at a bond line thickness nearly equal to the size of the plastic zone.

As mentioned earlier, there is no single trend to describe the dependence of the fracture energy of adhesive joints on bonding layer thickness and in some cases the proposals of Bascom et al. [3] and Kinloch and Shaw [6] do not correlate well with the experimental results. Ranade et al. [9] have studied the effect of the bond line thickness on the fracture energy under mode I loading conditions of aluminium specimens bonded with a structural epoxy adhesive. The bond line thickness varied from $0.02 \mathrm{~mm}$ up to $4.5 \mathrm{~mm}$. The fracture energies increased with an increase in the bond line thickness up to about $2 \mathrm{~mm}$ and remained constant out to the maximum bond line thickness of about $4.5 \mathrm{~mm}$. An estimate of the plastic zone length was obtained by testing bulk adhesive specimens and the result was compared to the experimental bond line thicknesses. The estimated plastic zone length was about one-fourth the bond line thickness value of about $2.2 \mathrm{~mm}$ (where a plateau of the fracture toughness was achieved). No detailed analysis of the crack path was reported and, consequently, the fracture toughness-adhesive bond thickness relation could not be fully understood. Daghyani et al. 
$[13,12]$ investigated the effect of bond thickness on the mode I fracture toughness of aluminium bonded joints. A rubber-toughened adhesive was used. The fracture toughness increased gradually up to $1 \mathrm{~mm}$ thick bond line, tending to a plateau afterwards. For bond line thicknesses larger than $4 \mathrm{~mm}$, there was a sharp increase in the fracture energy towards the fracture energy of the bulk adhesive material. The authors concluded that the relationship between the fracture energy and the bond thickness is mainly controlled by the plastic deformation of the adhesive around the crack tip as may be influenced by the constraint imposed by the adherends. Tough fracture mechanisms were observed in thick bonds and their presence became more pronounced with increasing adhesive bond line thickness. Cooper et al. [10] performed a combined experimental-numerical study of the fracture behaviour of a rubber-toughened epoxy adhesive. Metallic bonded joints with various bond line thicknesses ranging from 0.25 to 2.5 mm were tested. The fracture energies increased steadily from $2.6 \mathrm{~N} / \mathrm{mm}$ at $0.25 \mathrm{~mm}$ bond line thickness to $5.8 \mathrm{~N} / \mathrm{mm}$ at $1.3 \mathrm{~mm}$ and remained almost constant for larger bond line thicknesses. The authors argued that most of the energy dissipation occurs locally in the plastic zone formed ahead of the crack tip and that the intensity of local plasticity is the main factor in determining the fracture energy and not only the size of the plastic zone.

As aforementioned, in bonded joints with flexible adhesives, the adhesive bond line thickness also plays a role in mode I fracture behaviour and some studies have focused on this topic [14,4,16]. Banea et al. [14] investigated the effect of adhesive thickness on mode I fracture toughness of a high strength and flexible structural polyurethane adhesive. The fracture toughness increased linearly from a bond line thickness of $0.2 \mathrm{~mm}$ up to $1 \mathrm{~mm}$, whereas from 1 to $2 \mathrm{~mm}$ presented an increase of $20 \%$. The trend was justified by the development of plastic zones ahead of the crack tip of increased sizes prior to fracture, as the adhesive layer thickness increased. Maloney [4] also performed experiments with bonded joints consisting of aluminium adherends and an elastomeric adhesive (a silylmodified polymer). Two bond line thicknesses were tested: 1.1 and $4.1 \mathrm{~mm}$. The mode I fracture toughness increased with the adhesive bond line thickness. In order to better understand the damage mechanisms occurring during the crack growth, the adhesive layer was scanned by computed tomography. The joints of a bond line of $1.1 \mathrm{~mm}$ presented a higher concentration of voids near each interface than along the mid-plane of the adhesive layer. The adhesive along the free surfaces of the joints often failed in the last place, after the adhesive in the inner region has failed by cavitation due to a critical state of hydrostatic stress. Similar failure mechanisms were observed in joints with bond line thicknesses of $4.0 \mathrm{~mm}$. The joints also displayed voids along narrow strips of adhesive in the central region around $3 \mathrm{~mm}$ from any free surface, probably where the hydrostatic stress reached a critical value.

The study presented herein focuses on the adhesive bond line thickness effect on mode I fracture behaviour of steel to steel joints bonded with a structural epoxy adhesive by using the double cantilever beam (DCB) test. The range of adhesive bond line thicknesses considered was $0.4 \mathrm{~mm}$ to $10 \mathrm{~mm}$. Standard (i.e., the Simple Beam Theory (SBT), the Compliance Calibration Method (CCM) and nonstandard (i.e., the Penado-Kanninen (P-K) model) reduction methods were applied to the experimental load-displacement curves to evaluate the mode I strain energy release rate (SERR). The stress field ahead of the crack tip was assessed for the range of adhesive bond line thicknesses studied. The mode I SERR-adhesive bond line thickness relation was explained by the crack path location and the features found on the failure surfaces in conjunction with the stress field ahead of the crack tip.

\section{Experimental fracture tests}

\subsection{Specimens}

The mode I fracture toughness was determined from the double-cantilever beam (DCB) test. The DCB specimens (see Fig. 1) were made of $S 690$ steel adherends, with a thickness of $3.0 \mathrm{~mm}$, bonded with a structural two-component epoxy paste adhesive, Araldite 2015 (Huntsman $\left.^{\circledR}\right)$. Five adhesive bond line thicknesses were studied: 0.4, 1.1, 2.6, 4.1 and $10.1 \mathrm{~mm}$.
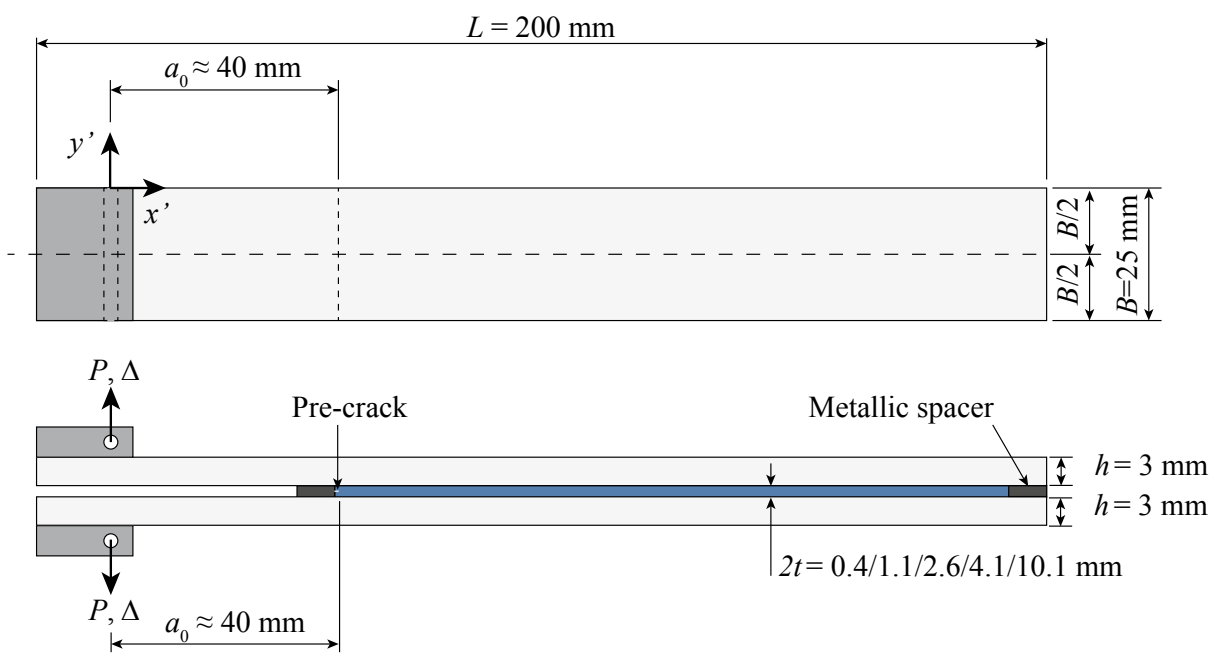

Fig. 1. Double-cantilever beam (DCB) specimen. 
Table 1

Mechanical properties of the steel S690 (according to supplier's datasheet) and the epoxy adhesive Araldite 2015 (experimentally measured from dog bone specimens cured $1 \mathrm{~h}$ at $80^{\circ} \mathrm{C}$ ). The \pm symbol defines the standard deviation of the results.

\begin{tabular}{ccccc}
\hline Material & Young's modulus (GPa) & $v$ & Yield strength (MPa) & Ultimate strength (MPa) \\
\hline Steel S690 & 210 & 0.3 & 770 & 832 \\
Epoxy adhesive & $2 \pm 0.3$ & 0.33 & $16.1 \pm 1.9$ & $28.8 \pm 0.7$ \\
\hline
\end{tabular}

Steel: yield strength $0.2 \%$; Adhesive: yield strength $0.1 \%$.

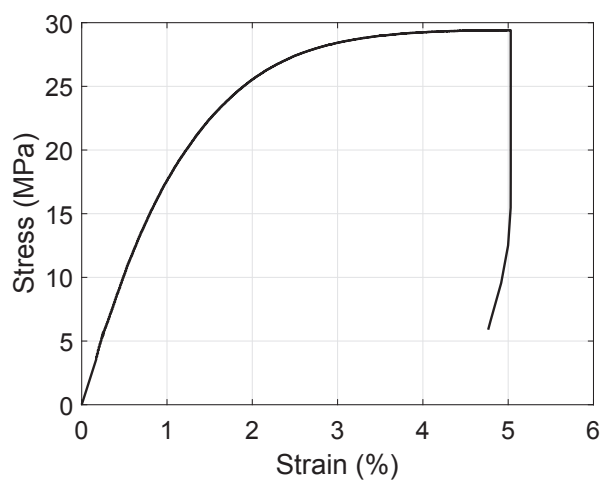

Fig. 2. Engineering stress-strain curve: Araldite 2015 cured $1 \mathrm{~h}$ at $80^{\circ} \mathrm{C}$.

The mechanical properties of the steel S690 and the epoxy adhesive are given in Table 1. The steel properties were taken from the supplier's technical datasheet, while the adhesive's mechanical properties were experimentally measured from tensile dog bone specimens with a thickness of $2 \mathrm{~mm}$ in accordance with ISO 527 [22]. The representative engineering stress-stress curve of the epoxy adhesive Araldite 2015 is shown in Fig. 2.

The steel adherends' surfaces were treated before the bonding process. All the surfaces were grit blasted using aluminium oxide (Corublast Super Z-EW nr. 100). Before and after grit blasting, the surfaces were cleaned with a clean cloth soaked with acetone. Afterwards, the steel surfaces were immersed in a potassium hydroxide solution (alkaline cleaner), which was stirred at $300 \mathrm{rpm}$ and heated to $60{ }^{\circ} \mathrm{C}$. The immersion in the solution lasted $10 \mathrm{~min}$. As a final step prior to bonding, the cleaned steel surfaces were immersed in a silane $\gamma$-glycidoxypropyltrimethoxysilane ( $\gamma$-GPS) solution for $20 \mathrm{~s}$ in order to strengthen the adhesion at the interfaces. The oven cure took place at $150{ }^{\circ} \mathrm{C}$ for $1 \mathrm{~h}$, afterwards. The silane solution was prepared in three steps, according to [23]. Firstly, the $\gamma$-GPS was hydrolysed in distilled water (DW)-methanol mixture. The volume ratios of $\gamma$-GPS/DW/methanol were $10 / 80 /$ 10, respectively. Secondly, the $\mathrm{pH}$ was set to $5-5.5$ by adding acetic acid to keep the solution's stability. Finally, the solution was magnetically stirred for $48 \mathrm{~h}$ at $300 \mathrm{rpm}$ at room temperature.

A manual applicator gun with a static-mixing nozzle was used to mix and apply the two-component epoxy paste adhesive, Araldite 2015. In order to have a correct mixture of both components, a small quantity of adhesive was in the first place discarded. Metallic spacers of 5 different thicknesses (approximately, 0.4, 1.1, 2.6, 4.1 and $10.1 \mathrm{~mm}$ ) were used to obtain a uniform adhesive bond line, as shown in Fig. 1. Two metallic stripes and a sharp razor blade were used to build the spacers. These components were bonded by a fast curing glue. The razor blade was placed in between the metallic stripes to create a pre-crack at the mid-thickness of the bond line. The spacers were treated with a release agent before the specimen parts were assembled. After the bonding, the oven cure took place at $80^{\circ} \mathrm{C}$ for $1 \mathrm{~h}$ according to the manufacturer's specifications. An even bond line thickness was obtained by making use of weights to uniformly compress the specimens. At least 4 specimens were manufactured per bond line thickness. The total thickness of the specimens was measured three times along the specimen length and the average was calculated in accordance with the ASTM D552813 [24]. The average bond line thickness was taken by subtracting the adherends' thickness.

After curing the specimens, the excess of adhesive on the sides was abraded off. For the crack length measurements, a thin layer of white paint was applied to the side of the specimens, and black speckles were painted on top of it. This preparation was done before any load was applied.

\subsection{Test set-up}

The fracture tests were performed on a $20 \mathrm{kN}$ (load-cell precision of $0.5 \%$ ) Zwick tensile test machine under a fixed displacement rate of $1 \mathrm{~mm} / \mathrm{min}$. The crack length was measured by means of a 3D image acquisition system placed at the side of the specimen. Pictures were taken every second. The crack length was defined as the straight and horizontal line distance between the load line and the crack tip, where the load line is supposed to be coincident with the centreline of the grips' pins. Moreover, it was assumed that any displacement occurring in the end-blocks is negligible compared to the displacement of the arms of the specimens. 


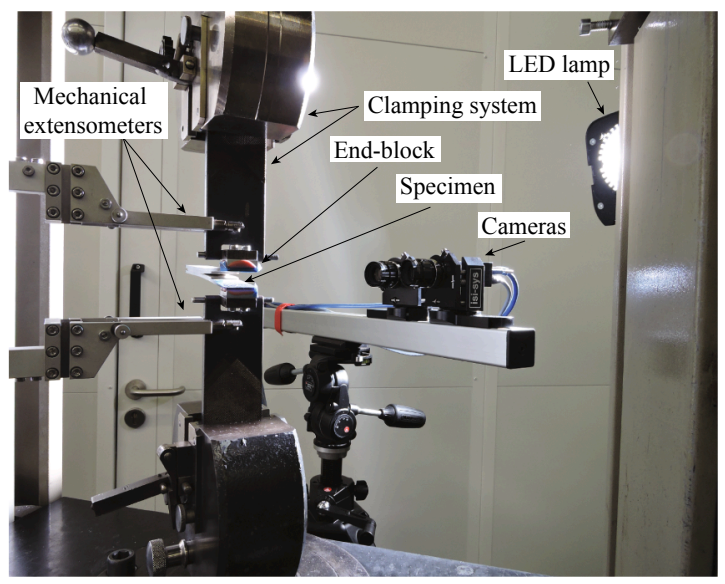

Fig. 3. Test set-up.

Fig. 3 shows an overview of the experimental test set-up, highlighting the mechanical extensometers (used to measure the total displacement of the specimen), the end-blocks and the 3D image acquisition system.

\subsection{Fracture surfaces analysis}

In order to evaluate the crack path location and to investigate the features of the fracture surfaces, a three-dimensional measuring microscope and a fringe projection scanner (Keyence VR-3200, Japan) were used. The scanner is characterized by $<100 \mathrm{~nm}$ out-ofthe plane resolution with up to a $200 \times 200 \mathrm{~mm}^{2}$ measuring area.

\section{Data reduction methods}

Using the Irwin-Kies compliance formula, the mode I strain energy release rate (SERR), i.e., the driving force for steady-state crack growth, can be expressed as

$$
G_{\mathrm{I}}=\frac{P^{2}}{2 B} \frac{d C}{d a}
$$

where $P$ is the applied load, $C$ is the specimen compliance, $B$ is the specimen width and $d a$ is the instantaneous crack length extension. A straight crack front is assumed. Standard methods for the mode I energy release calculation are based on Eq. (1), differing only in the way in which the derivative $d C / d a$ is obtained [17].

\subsection{Standard methods}

Literature suggests different methods to determine the specimens' compliance, $C$. Some methods are based on an analytical calculation, such as the Simple Beam Theory (SBT), while others are based on direct curve fitting of the measured compliance to the measured crack length, such as the Compliance Calibration Method (CCM) [24]. The adhesive layer thickness effect on $G_{\mathrm{I}}$ is indirectly taken into account in these methods when considering the experimental specimens' compliance. Indeed, the finite stiffness of the system, including the effects of the bond line, are effectively taken into account when experimental compliance is used, although the adhesive bond line thickness does not explicitly appear in the expression of $G_{\mathrm{I}}$.

\subsubsection{The Simple Beam Theory}

The mode I strain energy release rate based on the SBT is given by,

$$
G_{\mathrm{I}-\mathrm{SBT}}=\frac{P^{2} a^{2}}{B E I}=\frac{3 P}{B h} \sqrt[3]{\frac{4 P \Delta^{2}}{B E}} .
$$

where $a$ represents the crack length, $E$ is the Young's modulus of an isotropic beam, $\Delta$ is half of the total displacement and $I=\frac{B h^{3}}{12}$ defines the second moment of the beam cross-section area [24].

At fracture, the driving force equals the fracture energy, $G_{\mathrm{I}}=G_{\mathrm{Ic}}$, denoting the crack onset in the adhesive. The initial linear relation between load and displacement turns to a non-linear one during crack steady-state propagation. Assuming that $G_{\text {Ic }}$ is constant during propagation, $P$ and $\Delta$ scale as,

$$
P=\frac{B}{3} \sqrt[4]{\frac{3 E h^{3}}{4}} G_{\mathrm{Ic}}^{3 / 4} \cdot \Delta^{-1 / 2}=\psi \cdot \Delta^{-1 / 2}
$$


Eq. (3) provides a power-law for the steady-state, self-similar crack growth process [25].

\subsubsection{The Compliance Calibration Method}

From an empirical analysis, in the Compliance Calibration Method (CCM), the relation between $P, 2 \Delta$ and $a$ is expressed as [26],

$$
P_{\mathrm{CCM}}=\left(\chi^{-1} \cdot a^{-n}\right) \cdot 2 \Delta=\Omega \cdot 2 \Delta .
$$

The mode I strain energy release rate based on the CCM is expressed as,

$$
G_{\mathrm{I}-\mathrm{CCM}}=\frac{n P \Delta}{B a}=\frac{n P \Delta}{B\left(\frac{2 \Delta}{P \chi}\right)^{1 / n}}=\frac{n}{2^{1 / n} B} \cdot \chi^{1 / n} \cdot P^{\frac{n+1}{n}} \cdot \Delta^{\frac{n-1}{n}},
$$

where $n$ equals the slope of the $\log$ - $\log$ plot of $\Omega$ versus $a$ (i.e., $\log \Omega=-\log \chi-n \log a$ ). According to the SBT, $n$ should be equal to 3 [26].

Similarly, as explained in SBT, at crack onset and post-propagation, the driving force equals the fracture energy, $G_{\mathrm{I}}=G_{\mathrm{Ic}}$. Assuming that $G_{\mathrm{Ic}}$ is constant during the crack growth process, the load, $P$, as a function of $\Delta$ is given by,

$$
P=\left(\frac{B G_{\mathrm{Ic}}}{n}\right)^{\frac{n}{n+1}} \cdot\left(\frac{2}{\chi}\right)^{\frac{1}{n+1}} \cdot \Delta^{-\frac{(n-1)}{(n+1)}}=\beta \cdot \Delta^{-\frac{(n-1)}{(n+1)}} .
$$

\subsection{Penado-Kanninen model: the Euler-Bernoulli beam on the Winkler elastic foundation}

In the SBT, the bonded region is considered infinitely stiff. The crack tip opening displacement is, thus, 0 , so it is the root rotation, and the presence of the fracture process zone ahead of the crack tip is disregarded. However, in reality, the scenario is rather different. In fact, the beams are not fixed at the crack tip due to the flexibility of the adhesive layer. Indeed, this flexibility may lead to some vertical displacement of the beams within the bonded zone, inducing root rotation of the beams near the crack tip region. The Winkler elastic foundation was seemingly the first approach developed to depict the root rotation effect [27,28].

The Winkler correction for DCB specimens with softer and thicker interlayers was subject of the study of several researchers [29-32]. Penado [32] developed a method to determine the compliance and the energy release rate of the DCB specimen with an adhesive layer based on modifying the Kanninen's "augmented DCB model" ([29]) for crack propagation analysis of a homogeneous specimen. The Penado-Kanninen (P-K) model is obtained by considering a finite length beam, which is partially free (representing the unbonded part of the specimen) and partially supported by an elastic foundation (representing the bonded region), see Fig. 4. The DCB specimen is symmetric about the $x$-axis along the centreline of the adhesive layer. Only half of the specimen is represented in Fig. 4 (bond line of thickness $t$ ). The simplest theories are used: the Euler-Bernoulli beam theory and the Winkler foundation for the free and the bonded regions, respectively [25].

The solution of the displacement of the Penado-Kanninen beam model is given by,

$$
w(x)=\frac{P}{6 E I \lambda^{3}} \begin{cases}\left(3 a \lambda^{3} x^{2}-\lambda^{3} x^{3}+6 a \lambda^{2} x+3 \lambda a+3 \lambda x+3\right) & 0 \leqslant x \leqslant a \\ 3 e^{\lambda x}[\cos (\lambda x) a \lambda+a \sin (\lambda x) \lambda+\cos (\lambda x)] & -\infty \leqslant x \leqslant 0\end{cases}
$$

where $\lambda$ is the wave number, an inverse of which defines the elastic process zone length. The process zone length, $\lambda^{-1}$, in the context of the elastic foundation is interpreted as the distance (from the crack tip) over which the positive peel stress is distributed. The $\lambda^{-1}$ length exits beyond the crack tip due to the flexibility of the adhesive. The $\lambda$ is defined as,

$$
\lambda=\sqrt[4]{\frac{k}{4 E I}} \quad \text { where } \quad k=m_{\mathrm{q}}\left(\frac{E_{\mathrm{a}}}{t}\right) B
$$

where $E$ is the adherends' elastic modulus, $E_{\mathrm{a}}$ is the Young's modulus of the adhesive, $t$ is half of the thickness of the adhesive layer, and $B$ is the specimen width. Moreover, $k$ is the foundation modulus describing the stiffness of the springs and depends on the geometry and material properties of the adhesive. Finally, constant $m_{\mathrm{q}}(q=1-3)$ allows for the arbitrary formulation of the stress state at the crack front. Specifically, $m_{\mathrm{q}}$ is expressed as,

$$
m_{1}=1
$$

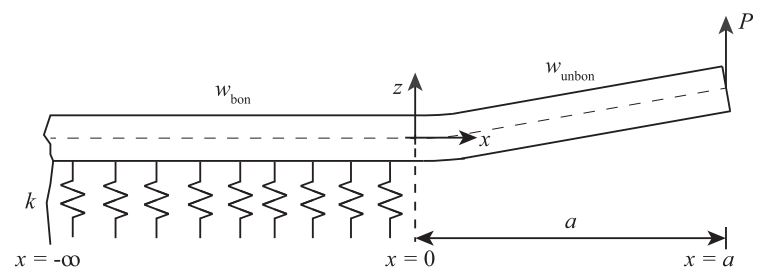

Fig. 4. DCB specimen modelled according to Kanninen-Penado model [25]. 
for the plane stress conditions in all directions (3D plane stress state) [33];

$$
m_{2}=\frac{1}{\left(1-v_{\mathrm{a}}^{2}\right)}
$$

for in-plane strain conditions and plane stress conditions in the transverse direction (2D plane strain state) [34];

$$
m_{3}=\frac{\left(1-v_{\mathrm{a}}\right)}{\left[\left(1-2 v_{\mathrm{a}}\right)\left(1+v_{\mathrm{a}}\right)\right]}
$$

for the plane strain conditions in all directions (3D plane strain state) [35]. $\nu_{\mathrm{a}}$ is the Poisson's ratio of the adhesive, presenting elastic or elasto-plastic behaviour. In the case of an (incompressible) elastomeric adhesive, the foundation modulus should be modelled differently and, hence, the interested reader is referred to [15,36] for more details.

The strain energy release rate is determined using the compliance method. The beam displacement at $x=a$ is given by,

$$
\Delta=w_{\text {unbon }}(x=a)=\frac{P}{E I \lambda^{3}}\left(\frac{1}{3} \lambda^{3} a^{3}+\lambda^{2} a^{2}+\lambda a+3\right) .
$$

The displacement given by Eq. (12) corresponds to half of the specimen. Therefore, the whole specimen displacement is equal to $2 \Delta$. The strain energy release rate, $G_{\mathrm{I}}$, is then given by,

$$
G_{\mathrm{I}-\mathrm{P}-\mathrm{K}}=\frac{P^{2}}{2 B} \frac{d C}{d a}=\frac{P^{2}}{B E I \lambda^{2}}\left(\lambda^{2} a^{2}+2 \lambda a+1\right)
$$

Eq. (8) seems of fundamental importance revealing an inherent effect of the adhesive thickness on the elastic process zone length, $\lambda^{-1}$. The foundation modulus $k$ decreases as the adhesive layer thickness increases, leading to smaller values of $\lambda$. As the elastic process zone length is the inverse of $\lambda$, its value increases with increasing adhesive layer thickness. The strain energy release rate is directly affected by the increase of the adhesive layer thickness.

\subsection{Mode I SERR: the relation between the Simple Beam theory and the Penado-Kanninen model}

The mode I energy release rate was previously derived from the Simple Beam theory and the Penado-Kanninen model, and is expressed as,

$$
\begin{aligned}
G_{\mathrm{I}-\mathrm{SBT}} & =\frac{P^{2} a^{2}}{B E I}, \\
G_{\mathrm{I}-\mathrm{P}-\mathrm{K}} & =\frac{P^{2}}{B E I \lambda^{2}}\left(\lambda^{2} a^{2}+2 \lambda a+1\right) .
\end{aligned}
$$

Eq. (15) can be re-written as,

$$
G_{\mathrm{I}-\mathrm{P}-\mathrm{K}}=G_{\mathrm{I}-\mathrm{SBT}} \cdot\left(1+\frac{2}{\lambda a}+\frac{1}{\lambda^{2} a^{2}}\right)
$$

Eq. (16) reveals that the value of $G_{\mathrm{I}-\mathrm{P}-\mathrm{K}}$ tends to the value of $G_{\mathrm{I}-\mathrm{SBT}}$ when $\lambda a \rightarrow \infty$, which means that the bonded region would be infinitely stiff and, consequently, the opening displacement, as well as the root rotation at the crack tip, would be null.

\section{Results}

\subsection{Load-displacement curves}

The test results corresponding to the representative specimens of each bond line thickness are shown in Fig. 5. The experimental load-displacement, $P-2 \Delta$, curves are consistent for each specimen within the same test series. In fact, the initial stiffness and peak load were similar in each of them as well as the post-peak region, from the crack onset up to complete failure. The average peak load is summarized in Table 2 .

Moreover, in Fig. 5 are also plotted analytical predictions of the experimental curves. The initial linear part of the $P$ - $2 \Delta$ curve is predicted based on the SBT $\left(P=\frac{3}{2} E I \frac{2 \Delta}{a_{0}^{3}}\right)$ and the P-K model (from Eq. (12)). The propagation region is predicted from the SBT and the CCM. For each representative specimen, the average values of $G_{\mathrm{I}}$ by applying the SBT and the CCM are determined and used as $G_{\mathrm{Ic}}$ in Eqs. (3) and (6), respectively. Concerning the SBT prediction, please note that the estimated crack length $\left(a_{\mathrm{SBT}}=\sqrt[3]{\frac{3}{2} E I \frac{2 \Delta}{P}}\right)$ is used to calculate $G_{\mathrm{I}}$ as reported by $[28,37]$. Finally, the experimentally measured crack lengths are plotted as a function of the displacement (the crack length range is restricted by the area analysed by the acquisition image system). The points highlighted in Fig. 5 are used in Section 5 for P-K model validation. 


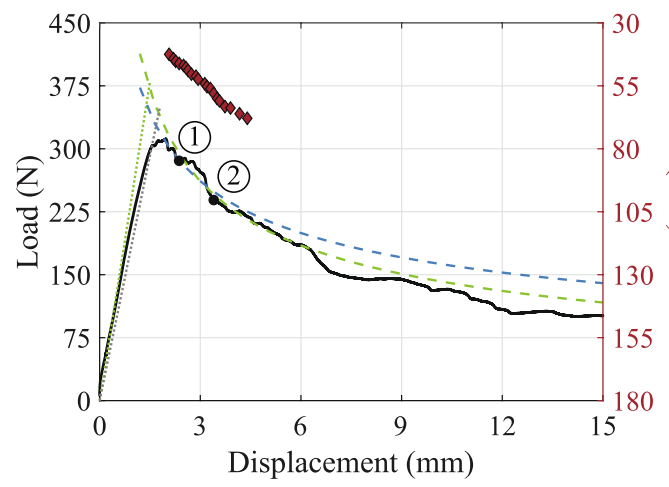

(a) $2 t=0.4 \mathrm{~mm}$

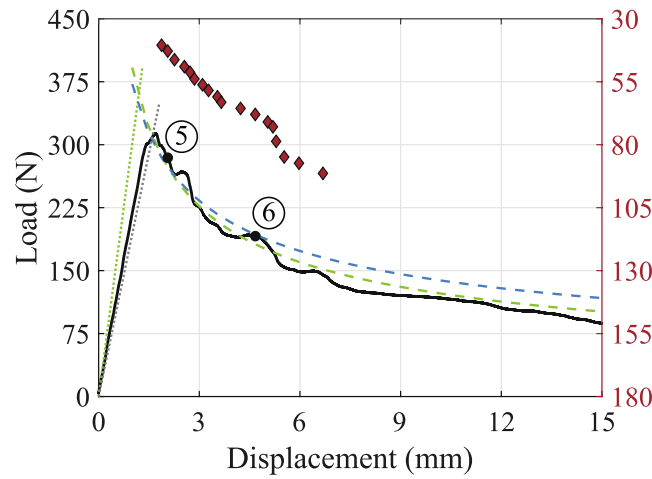

(c) $2 t=2.6 \mathrm{~mm}$

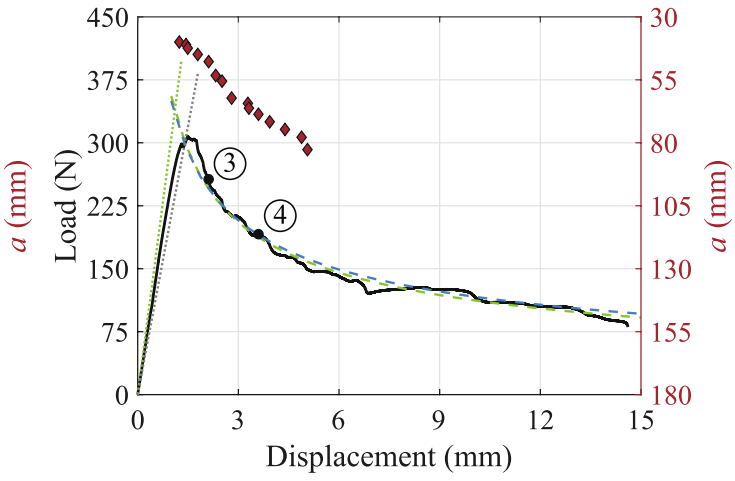

(b) $2 t=1.1 \mathrm{~mm}$.

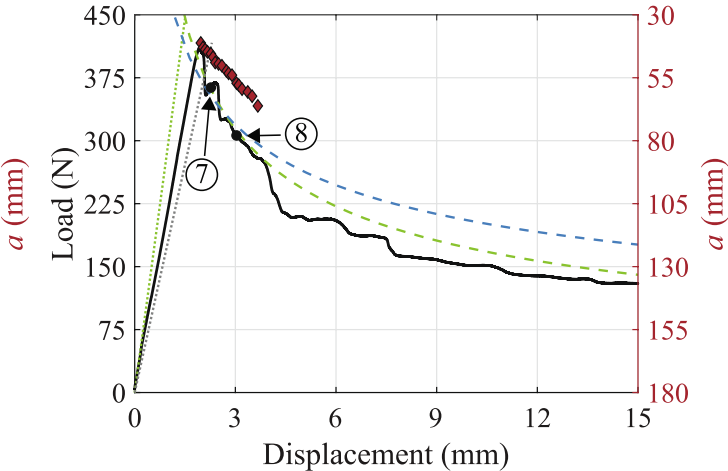

(d) $2 t=4.1 \mathrm{~mm}$.

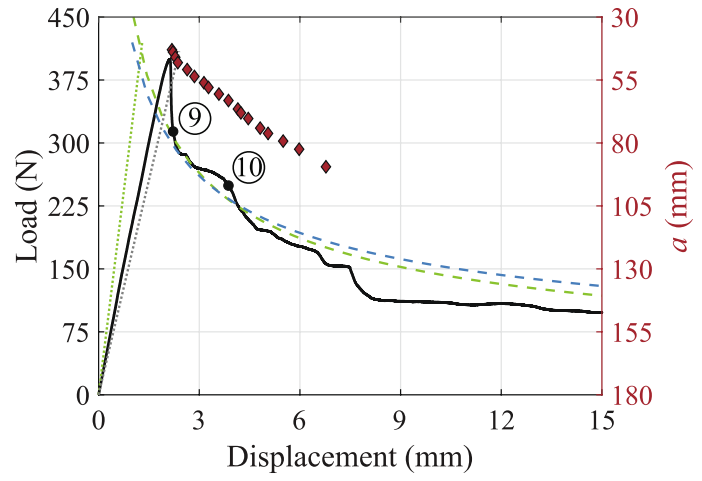

Experiment --- SBT propagation
SBT initiation --- CCM propagation
P-K initiation $\diamond$ Visual $a$

(e) $2 t=10.1 \mathrm{~mm}$.

Fig. 5. Load-displacement curves (experiment vs. predictions) and experimentally measured crack lengths. The points highlighted are used in Section 5 for P-K model validation.

Table 2

Average peak load and corresponding standard deviation per bond line thickness.

\begin{tabular}{cccccc}
\hline $2 t$ & $0.4 \mathrm{~mm}$ & $1.1 \mathrm{~mm}$ & $2.6 \mathrm{~mm}$ & $4.1 \mathrm{~mm}$ & $10.1 \mathrm{~mm}$ \\
\hline \multirow{2}{*}{ Peak Load } & $311 \pm 18.2$ & $304 \pm 12.7$ & $308 \pm 18.2$ & $413 \pm 8.4$ & $380 \pm 15.8$ \\
\hline
\end{tabular}




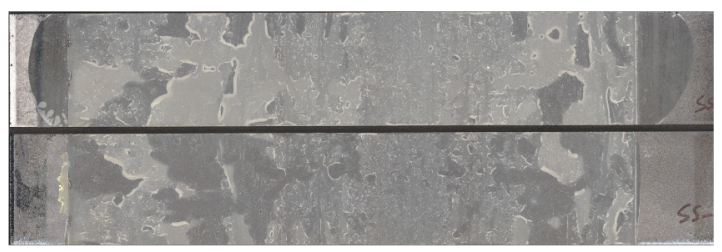

(a) $2 t=0.4 \mathrm{~mm}$

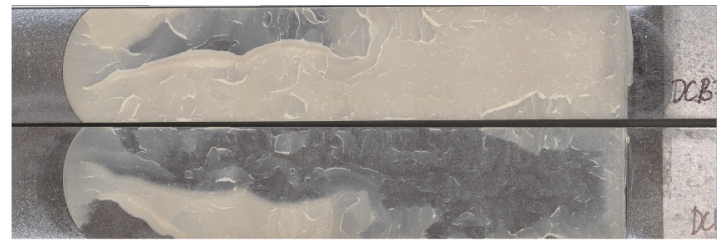

(b) $2 t=1.1 \mathrm{~mm}$

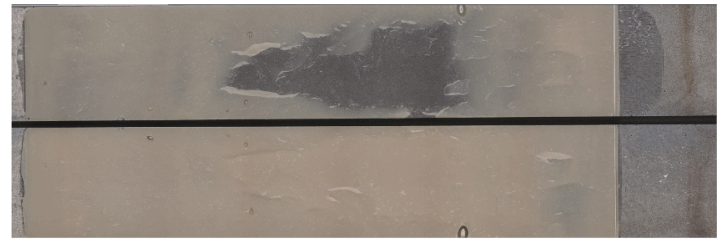

(c) $2 t=2.6 \mathrm{~mm}$.

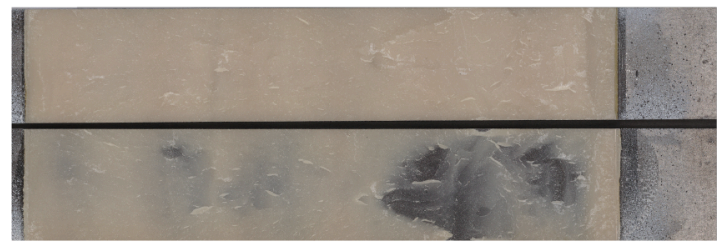

(d) $2 t=4.1 \mathrm{~mm}$.

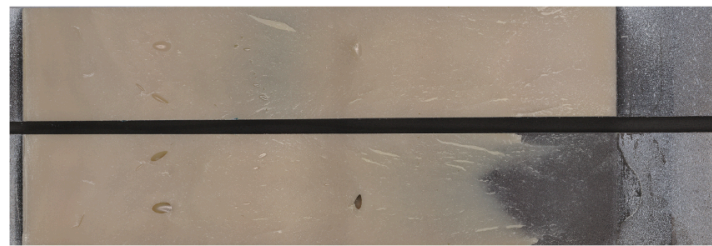

(e) $2 t=10.1 \mathrm{~mm}$.

Fig. 6. Failure surfaces of the representative specimens per bond line thickness - optical view.

\subsection{Failure surfaces}

The failure surfaces of the representative specimen of each bond line thickness are shown in Fig. 6, which exhibit cohesive failure (i.e., the crack propagated within the adhesive layer). In order to evaluate the crack path location and to investigate the features of these surfaces, a three-dimensional measuring microscope and a fringe projection scanner (Keyence VR-3200, Japan) were used. These measurements are presented in Fig. 7 (only one of the two failure surfaces is shown). The colour bar refers to the height of the adhesive remaining on the adherend surface. The bare steel regions (dark blue) were defined as the reference surface. There is some variation on the average bond line thickness within each set of specimens per bond line thickness, which leads in some cases to average bond line thicknesses higher than the average nominal thickness. However, unique features can be found on each set of the steel-steel DCB specimens. Even inside each set, different waviness and corresponding roughness profiles can be noticed on the failure surfaces, which explains the non-smooth behaviour of each $P-2 \Delta$ curve. The average areal roughness, $S_{\mathrm{a}}$, and the root mean square deviation, $S_{\mathrm{q}}$, of the entire failure surface (Area Total) and some arbitrary regions (Areas 1-4 in Fig. 7) of each representative specimen are given in Table 3 (a Gaussian filter is applied according to ISO 25178-2:2012. $S_{\mathrm{a}}$ is the arithmetic average of the absolute values of the profile height deviations from the mean line (defined by the waviness), $S_{\mathrm{q}}$ is the root mean square of the profile height deviations from the mean line).

Fig. 8 presents the longitudinal profiles of the failure surfaces of the representative specimens and thus the overall crack path profile. The height profile of the remaining adhesive layer on the failure surface in respect to the reference surfaces (dark blue regions 


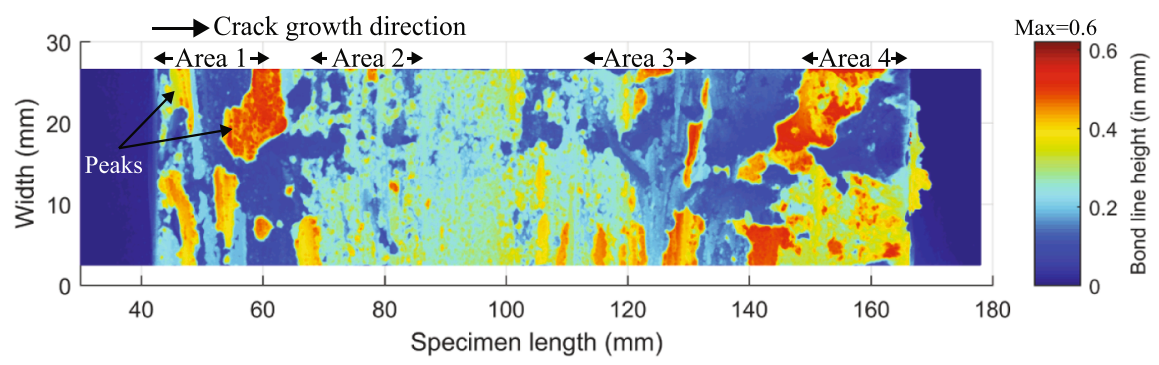

(a) $2 t=0.4 \mathrm{~mm}$.

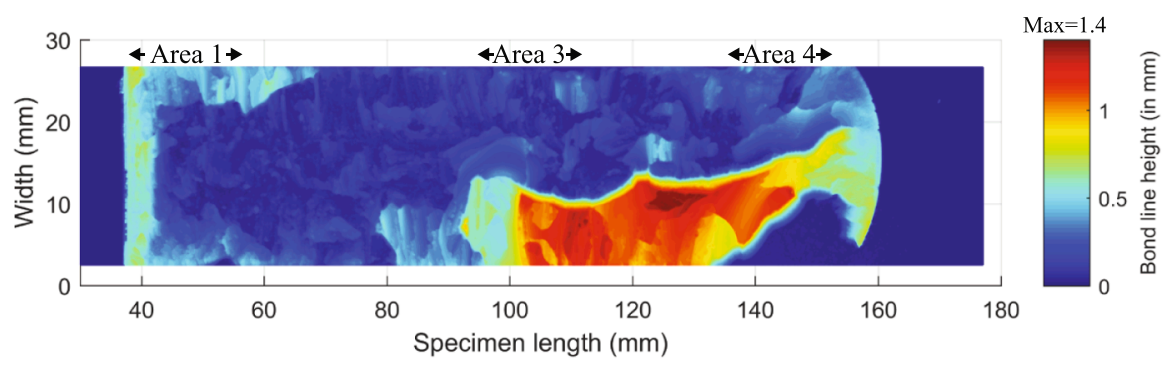

(b) $2 t=1.1 \mathrm{~mm}$.

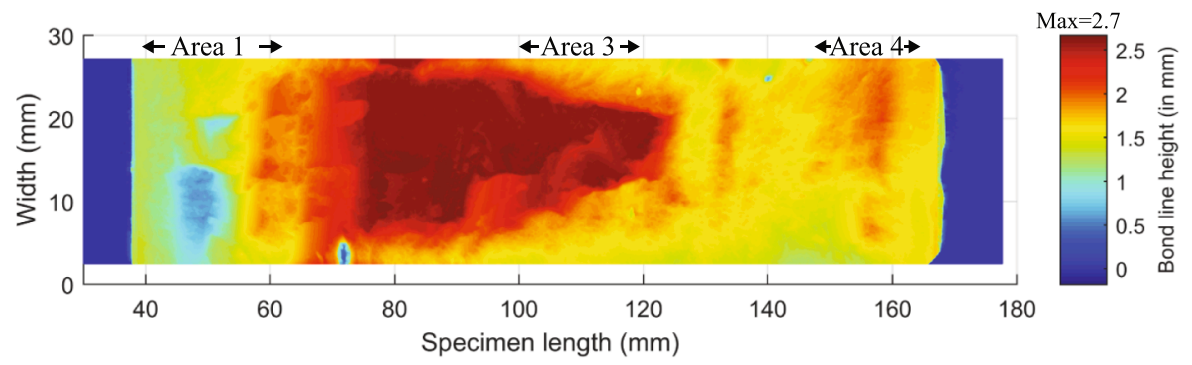

(c) $2 t=2.6 \mathrm{~mm}$.

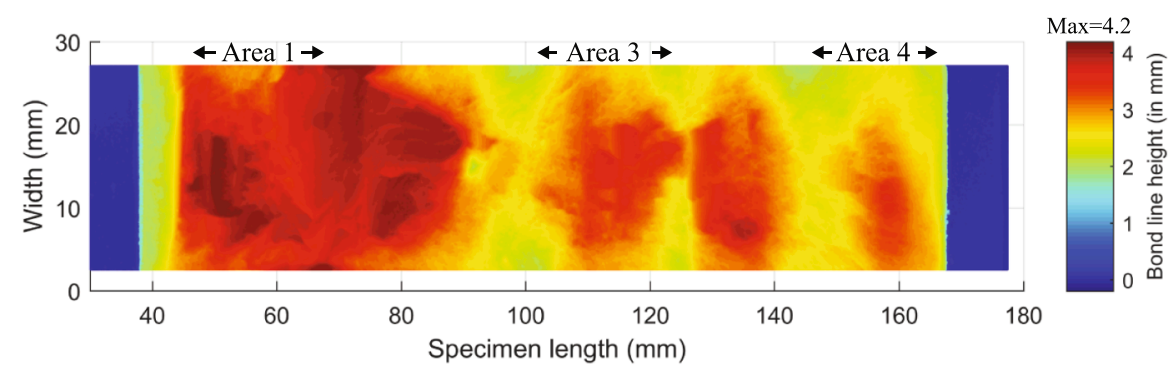

(d) $2 t=4.1 \mathrm{~mm}$.

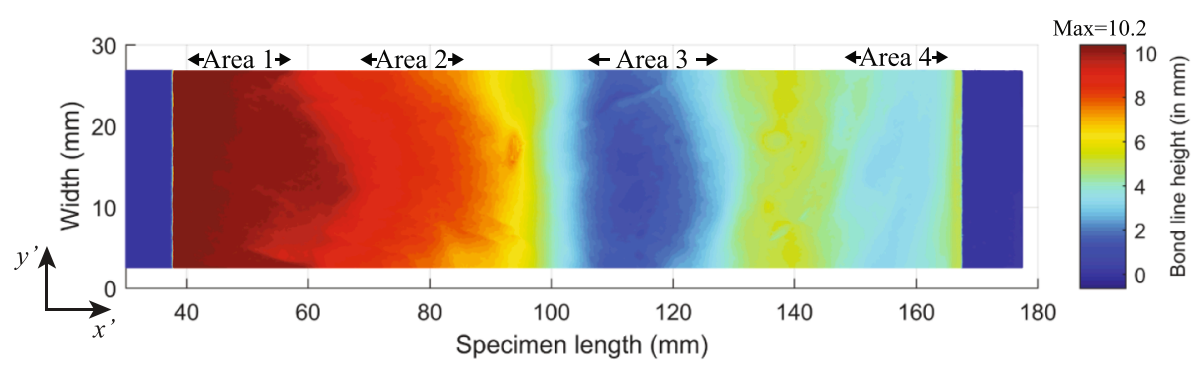

(e) $2 t=10.1 \mathrm{~mm}$. 
Fig. 7. Failure surfaces of the representative specimens per bond line thickness - height view. The colour bar refers to the height of the adhesive remaining on the adherend surface. The bare steel regions (dark blue) were defined as the reference surface (for interpretation of the references to colour in the colour bar, the reader is referred to the web version of this article).

Table 3

The average areal roughness, $S_{\mathrm{a}}$, and the root mean square deviation, $S_{\mathrm{q}}$, of the representative specimen of each test series. Area Total corresponds to the entire fracture surface, excluding the edges. The other areas are represented on each representative specimen in Fig. 7.

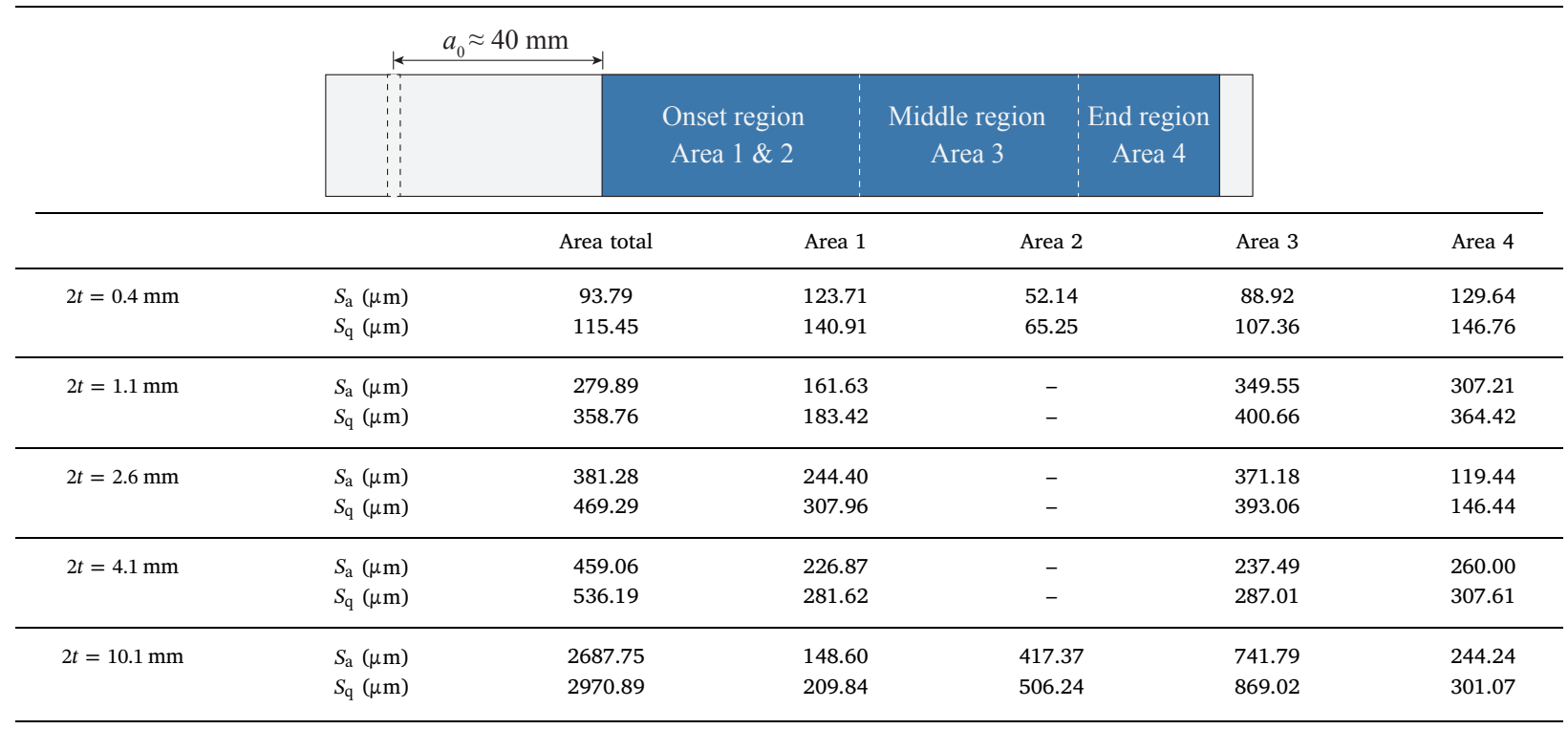

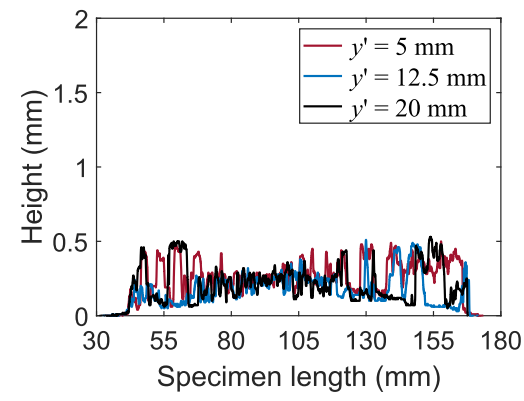

(a) $2 t=0.4 \mathrm{~mm}$.

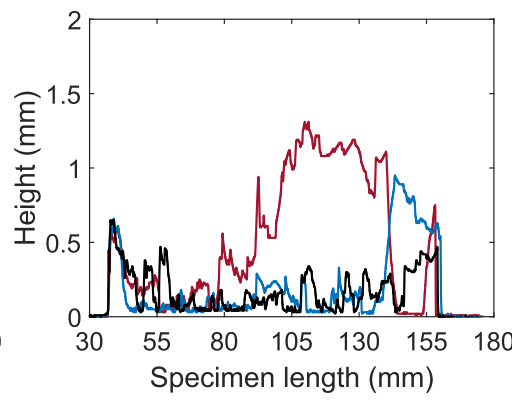

(b) $2 t=1.1 \mathrm{~mm}$.

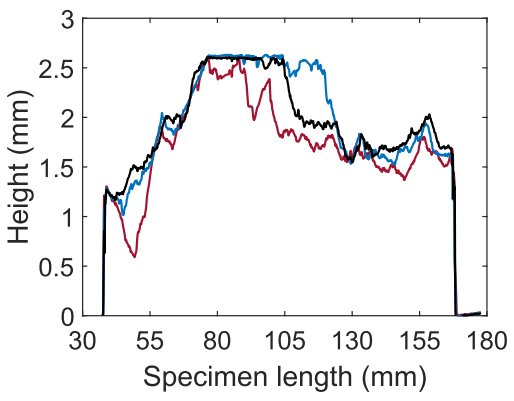

(c) $2 t=2.6 \mathrm{~mm}$.

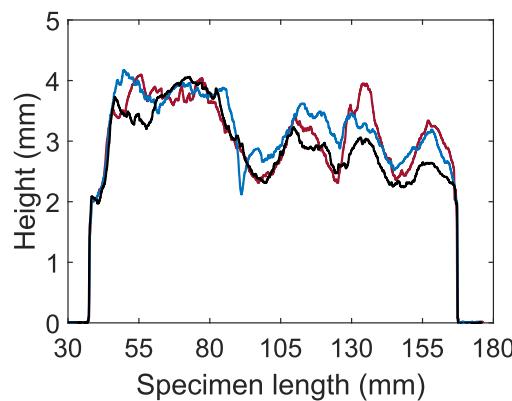

(d) $2 t=4.1 \mathrm{~mm}$.

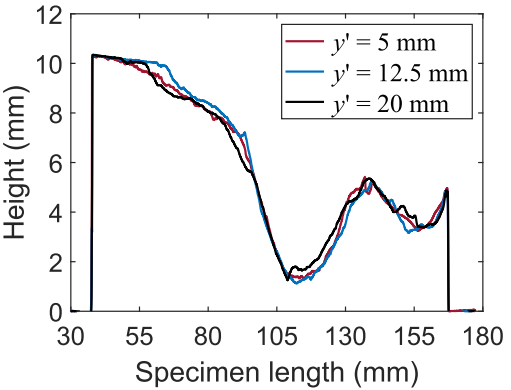

(e) $2 t=10.1 \mathrm{~mm}$.

Fig. 8. Height profile of the remaining adhesive layer on the failure surface in respect to the reference surfaces (dark blue regions in Fig. 7) along the specimen' s length direction of the representative specimens: (a) Bond line thickness ( $2 t$ ) of $0.4 \mathrm{~mm}$; (b) $2 t=1.1 \mathrm{~mm}$; (c) $2 t=2.6 \mathrm{~mm}$; (d) $2 t=4.1 \mathrm{~mm}$; (e) $2 t=10.1 \mathrm{~mm}$. The height profile is plotted at $y^{\prime}=5,12.5$ and $20 \mathrm{~mm}$ (for interpretation of the references to colour in the colour bar, the reader is referred to the web version o.f this article). 
in Fig. 7) is plotted along the specimens' length direction, more precisely at three specific values of the specimen width, namely at $y^{\prime}=5,12.5$ and $20 \mathrm{~mm}$. In fact, Fig. 8 shows that the height profiles of all specimens do not coincide along the specimen's width, being the more uniform the representative specimen with the thickest bond line of $10.1 \mathrm{~mm}$. This means that the failure surfaces are not symmetric along the width and, therefore, the crack front did not propagate uniformly along the width direction.

In the representative specimen with the thinnest bond line (i.e., approximately of $0.4 \mathrm{~mm}$ ), the failure surface is, in the initial part (from the initial crack length up to $70 \mathrm{~mm}$ ), characterized by some peaks, as is highlighted in Fig. 7(a). This region is followed by a smoother one, where the crack seems to propagate in the mid-thickness of the bond line (i.e., perfectly cohesive propagation). This feature can also be observed in Fig. 8(a). More heavy peaks appear afterwards, for crack lengths larger than $100 \mathrm{~mm}$. The $S_{\mathrm{a}}$ and $S_{\mathrm{q}}$ were determined in some arbitrary regions and the results corroborate the description presented previously, see Table 3 . By increasing the adhesive bond line thickness up to $1.1 \mathrm{~mm}$, the crack kept propagating inside the adhesive layer, however in a plane more remote from the mid-bond line thickness plane. Although the crack path approached regions really close to the epoxy-steel interface, it should be noticed that interfacial failure did not take place (a thin layer of adhesive is found on the complementary failure surface). As can be seen in Figs. 7(b) and 8(b), for crack lengths larger than $80 \mathrm{~mm}$, two different regions can be observed and the failure surface asymmetry along the width direction becomes more pronounced.

In the representative specimens with bond lines of 2.6 and $4.1 \mathrm{~mm}$, the crack started propagating in the mid-thickness of the adhesive layer, as shown in Fig. 8(c) and (d), respectively. However, its locus direction changed towards regions close to one of the epoxy-steel interfaces, afterwards. As previously commented, interfacial failure never took place. In the final region of the failure surface of the $2.6 \mathrm{~mm}$ thick bond line specimen, the crack propagated in a more central plane (i.e., near the mid-thickness of the adhesive layer). The average areal roughness and corresponding standard deviation were determined in arbitrary regions (Fig. 7 (c) and (d)) to show the changes on the local average roughness and the results are presented in Table 3. Finally, in the thickest specimens, with a bond line thickness of $10.1 \mathrm{~mm}$, the crack onset moved towards the steel-epoxy interface due to geometry singularity (Figs. $7(\mathrm{e})$ and $8(\mathrm{e})$ ) [38,39]. This change on the crack initiation location led to propagation along one of the steel interfaces. The presence of a thin layer of adhesive on these regions of the failure surfaces is indicative of the non-occurrence of adhesive failure. During the crack growth, the crack propagated through the weakest regions throughout the thickness and longitudinal directions of the bonded area, leading to a change on the crack propagation plane. For instance, in Fig. 7(e) is shown that the crack propagated from a region close to one interface to a region close to the second interface in the crack length range of 60-120 mm.

The fact that the average areal roughness, $S_{\mathrm{a}}$, does not provide any information on the shape, size or frequency of surface features is worthy of comment. The fracture energy of a bonded joint is dependent on the parameters mentioned in the last sentence. For example, the average areal roughness of Area 1 of the representative specimens with a bond line thickness of 0.4 and $1.1 \mathrm{~mm}$ is 123.71 and $161.63 \mu \mathrm{m}$, respectively. In the former specimen, this area is characterized by several peaks, whereas in later specimen a smoother area is found. The surface with the higher frequency of peaks is expected to lead to higher fracture energy as the total surface area is larger and thus more external work is needed for crack growth. The results of the fracture energy are presented in the next sub-section.

\subsection{Resistance-curves}

The Resistance-curves, also called as $R$-curves, of the representative specimens of two adhesive bond line thicknesses are presented in Fig. 9. The mode I fracture toughness is plotted against the experimentally measured crack length. Three curves are shown, which are determined based on: the SBT (Eq. (2)), the CCM (Eq. (5)) and the Penado-Kanninen model (Eq. (13)). It is important to call attention to the fact that the experimentally measured crack lengths are plotted in Fig. 5, allowing the correlation between the $R$ -

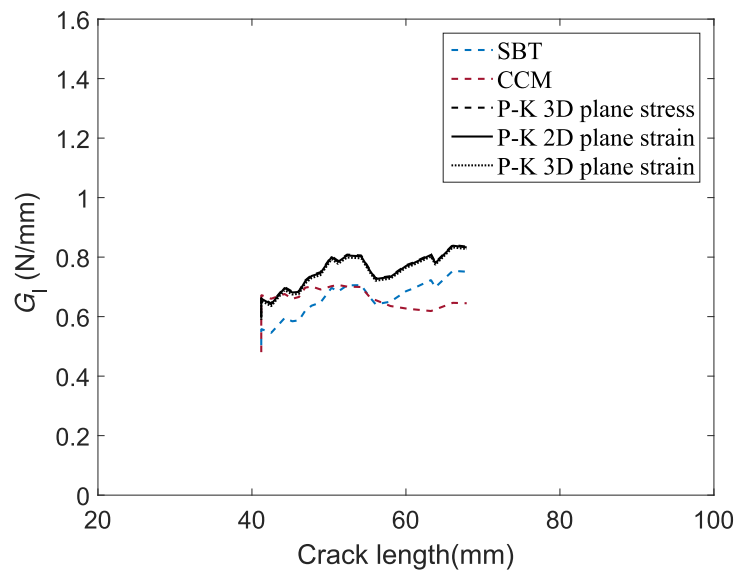

(a) $2 t=0.4 \mathrm{~mm}: R$-curve.

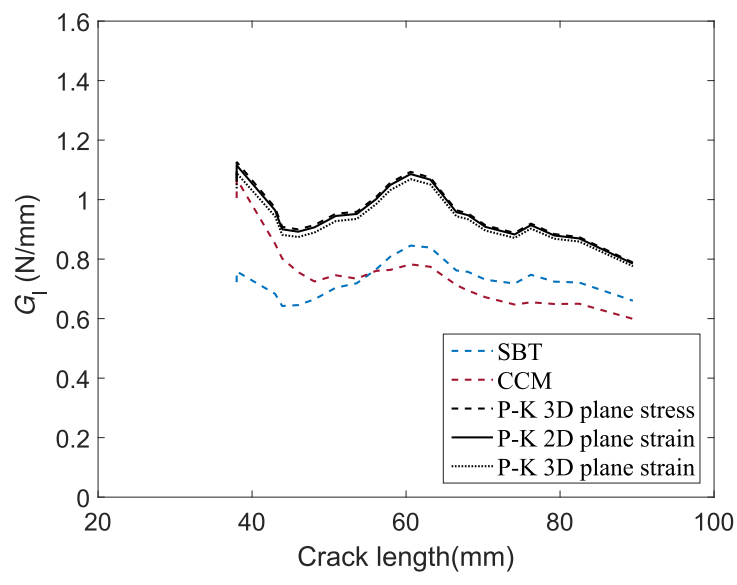

(b) $2 t=10.1 \mathrm{~mm}: R$-curve.

Fig. 9. Resistance-curves of the representative specimens of two bond line thicknesses: the mode I fracture toughness is plotted against the experimentally measured crack length. 
Table 4

Penado-Kanninen model: the effect of the stress state at the crack tip, of the adhesive's Poisson's ratio $\nu_{\mathrm{a}}$ and of the bond line thickness on the coefficient $m_{\mathrm{q}}$, the foundation modulus $k$ and the wave number $\lambda$.

\begin{tabular}{|c|c|c|c|c|c|}
\hline \multirow[b]{2}{*}{$v_{\mathrm{a}}(-)$} & \multirow{2}{*}{$\frac{2 t}{q(-)}$} & \multicolumn{2}{|c|}{$0.2 \mathrm{~mm}$} & \multicolumn{2}{|c|}{$10.1 \mathrm{~mm}$} \\
\hline & & $k(\mathrm{GPa})$ & $\lambda\left(\mathrm{mm}^{-1}\right)$ & $k(\mathrm{GPa})$ & $\lambda\left(\mathrm{mm}^{-1}\right)$ \\
\hline \multirow[t]{3}{*}{0.33} & $\mathrm{~m}_{1}=1.00$ & 250 & 0.27 & 10 & 0.12 \\
\hline & $\mathrm{m}_{2}=1.12$ & 281 & 0.28 & 11 & 0.12 \\
\hline & $\mathrm{m}_{3}=1.48$ & 370 & 0.30 & 15 & 0.13 \\
\hline \multirow[t]{3}{*}{0.4} & $\mathrm{~m}_{1}=1.00$ & 250 & 0.27 & 10 & 0.12 \\
\hline & $\mathrm{m}_{2}=1.19$ & 298 & 0.28 & 12 & 0.13 \\
\hline & $\mathrm{m}_{3}=2.14$ & 536 & 0.33 & 21 & 0.15 \\
\hline
\end{tabular}

$E_{\mathrm{a}}=2 \mathrm{GPa} ; E=210 \mathrm{GPa} ; B=25 \mathrm{~mm} ; h=3 \mathrm{~mm}$.

curves and the corresponding $P-2 \Delta$ curves. Moreover, the effect of the stress state at the crack tip on the fracture toughness is also evaluated by using three different $m_{\mathrm{q}}$ coefficients to calculate the $G_{\mathrm{I}-\mathrm{P}-\mathrm{K}}$. Regardless of the bond line thickness, the three curves (i.e., P$\mathrm{K}$ plane stress, P-K plane strain 2D, and P-K plane strain 3D) present almost identical results. Table 4 summarizes the effect of the stress state at the crack tip, of the Poisson's ratio $\nu_{\mathrm{a}}$ and of the adhesive bond line thickness, $2 t$, on the foundation modulus and the wave number, $k$ and $\lambda$, respectively. The correction made in order to allow for plane strain conditions at the crack tip is not negligible for adhesives with high Poisson's ratio (for example, $v_{\mathrm{a}}=0.4$ ). Indeed, for such adhesive, the value of $k$ by considering 3D plane strain conditions is almost twice the value of $k$ given by the 3D plane stress conditions, regardless of the bond line thickness. However, as the studied adhesive, Araldite 2015, has a Poisson's ratio of 0.33 , the correction for the plane strain conditions is not necessary.

The $G_{\text {I-P-K }}$ gives higher values than the $G_{\text {I-SBT }}$, which is expected according to Eq. (16), and the difference between the SBT and the P-K curves gets larger as the adhesive bond line increases. The thicker the bond line, the higher the amount of energy dissipated by plastic deformation in the adhesive layer in the region ahead of the crack tip due to larger plastic deformation zones. In fact, the foundation modulus varies inversely with the bond line thickness, and, consequently, an increase in the bond line thickness leads to a smaller $k$ and a smaller value of $\lambda$ (from Eq. (16) - see Table 4). Therefore, as $\lambda$ appears as a denominator in the terms inside the parentheses in Eq. (16), the factor, by which $G_{\text {I-SBT }}$ is multiplied to obtain $G_{\text {I-P-K }}$, increases leading to a higher offset in the fracture toughness curves of both methods.

Regardless of the adhesive bond line thickness (and the methodology employed), the $R$-curves are characterized by a peaked or "saw-tooth" appearance, which shows that no steady-state, self-similar regime was reached (i.e., $G_{\mathrm{I}}$ is not constant in the propagation region). Indeed, in Section 4.2 was demonstrated that the crack did not always propagate along the same plane (i.e., along the same adhesive layer height). These changes on the crack path position along the adhesive layer thickness are also reflected in the experimental $P-2 \Delta$ curves by the non-smooth behaviour (see Fig. 5). Looking at the crack locus, this means that its direction has several times changed during the crack growth process and, consequently, it has affected the plastic zone size and shape. As energy dissipation mainly occurs in the plastic deformation zone, the non self-similar regime in the $R$-curves is then attributed to the alteration of the size of this zone. More details about the variation of the mode I fracture toughness on each bond line thickness are given in Section 5 .

Hereinafter, only the results considering $m_{3}$ are reported because the mode I fracture toughness results kept independent of the stress state considered, see Fig. 9.

\subsection{Analytical load-displacement curves}

As aforementioned, analytical predictions of the initial linear part and crack growth region are shown in Fig. 5. By considering a $G_{\mathrm{I}}=G_{\mathrm{Ic}}=$ const. during the propagation process, an analytical P-2 $\Delta$ curve can be obtained from the SBT and the CCM. For each representative specimen, the average values of $G_{\mathrm{I}}$ by applying the SBT and the CCM are determined and used as $G_{\text {Ic }}$ in Eqs. (3) and (6), respectively. Concerning the SBT prediction, please note that the estimated crack length $\left(a_{\mathrm{SBT}}=\sqrt[3]{\frac{3 E I 2 \Delta}{2 P}}\right)$ is used to calculate $G_{\mathrm{I}}$ as reported by $[28,37]$. Two examples of the $\log \Omega-\log a$ relation are shown in Fig. 10 and the average value of the exponent $n$ determined for each representative specimen is presented in Table 5.

The initial linear part of the experimental $P$-2 $\Delta$ curves (see Fig. 5) is estimated from the SBT $\left(P=\frac{3 E I 2 \Delta}{2 a_{0}^{3}}\right)$ and the P-K model (from Eq. (12)). The SBT prediction matches well the DCB specimens with thin adhesive bond lines (i.e., $2 t=0.4-1.1 \mathrm{~mm}$ ). By increasing $2 t$, the level of agreement between the analytical and experimental curves gets lower. On the other hand, the P-K model predicts the behaviour rather well in the range of bond line thicknesses of $0.4-2.6 \mathrm{~mm}$. For thicker bond lines (i.e., of 4.1 and $10.1 \mathrm{~mm}$ thick), the predicted compliance by the P-K model is higher than the experimental as the crack has propagated asymmetrically close to one of the two interfaces for both cases. These results were expected because the SBT does not allow for flexibility of the bonded joint near the crack front (the beams are assumed to be fixed at the crack front), leading to an overestimation of the experimental stiffness. This flexibility effect becomes more meaningful as the bond line thickness gets thicker and thicker.

In the propagation region (see Fig. 5), the SBT gives better predictions than the CCM. Good agreement between experimental data 


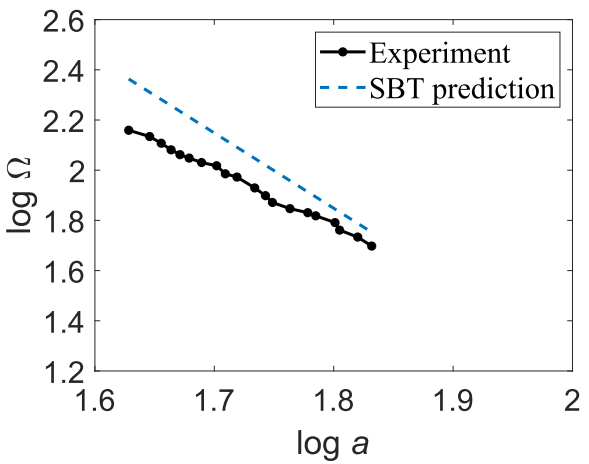

(a) $2 t=0.4 \mathrm{~mm}$.

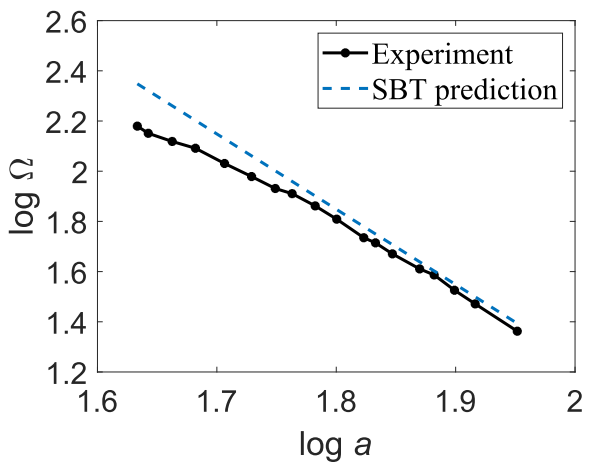

(b) $2 t=10.1 \mathrm{~mm}$.

Fig. 10. $\log \Omega-\log a$ relation (experiment vs. prediction).

and the theoretical SBT relation was also shown by Budzik et al. [28] and Salem et al. [37]. Eq. (3) provides a power-law for steadystate, self-similar crack growth. However, the experimental results display non-smooth behaviour and, as shown previously in the $R$ curves of each representative specimen, a steady-state condition was not reached during the experiments. This fact explains the differences between the analytical and experimental $P-2 \Delta$ curves. Finally, the accuracy of the CCM predictions depends on the evaluation of the parameters $n$ and $\chi$, which gets more precise for a larger number of data (i.e., when the range of crack lengths experimentally measured is larger, there will be a better fitting of the entire propagation region). For a better agreement of the CCM predictions, $n$ and $\chi$ should be updated for every increment of $a$. However, by using the average values of these two parameters (i.e., $n$ and $\chi$ ), good predictions are obtained in the range of the experimentally measured crack lengths. Alternatively, the critical fracture energy or the $\psi$ (from Eq. (3)) could be updated for the SBT model, which would allow considering the more local character of $G_{\text {Ic }}$.

\section{Adhesive bond line thickness effect on mode I fracture toughness}

Fig. 11 shows the trend of mode I fracture toughness based on the P-K model, Eq. (13), considering $m_{3}-3 \mathrm{D}$ plane strain (note that only these results are plotted because the mode I fracture toughness results kept independent of the stress state considered, see Fig. 9) as a function of the adhesive bond line thickness. The maximum (" $\Delta$ " symbol) and minimum (" $\nabla$ " symbol) values of $G_{\mathrm{I}}$ of each single specimen are represented and plotted against the average thickness of the corresponding bond line (the bond line was measured three times along the specimen length and the average was calculated). Two error bars are also plotted, giving the range of scatter on the thickness and $G_{\mathrm{I}}$ results of each bond line thickness. The average value of $G_{\mathrm{I}}$, which is represented by a bullet point, "•", corresponds to the mean of all points (maximum and minimum) plotted for each bond line thickness. The deformation zone length ahead of the crack tip of each bond line thickness is also plotted, i.e., $2 r_{\mathrm{p}}+\lambda_{j \text {-exp }}^{-1}$ where $j=0.4,1.1,2.6,4.1,10.1 \mathrm{~mm}$ and $\lambda_{j \text {-exp }}^{-1}$ corresponds to the value of the experimental $\lambda^{-1}$ of thickness of $j \mathrm{~mm}$ (more details about the calculation of $2 r_{\mathrm{p}}$ and $\lambda_{j \text {-exp }}^{-1}$ are shown later in this section). For clarity, the deformation zone length comprises both the plastic zone length and the elastic fracture process length, $\lambda_{j \text {-exp }}^{-1}$ The energy dissipation mainly occurs in the plastic deformation zone. However, the elastic process length also contributes to the work done by the external applied displacement.

Overall, a good agreement between the minimum and maximum values of $G_{\mathrm{I}}$ was found (i.e., the minimum and maximum values of $G_{I}$ form two distinct groups), as can be seen in Fig. 11. The results of the specimens with a bond line thickness of 0.4 mm were the exception, which is justified by the different waviness and corresponding roughness profiles found out in the failure surfaces of each

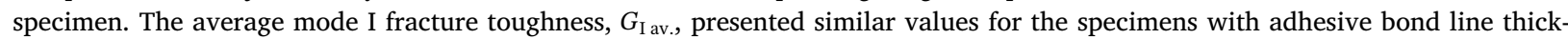
nesses of $0.4,1.1$ and $2.6 \mathrm{~mm}\left(G_{\mathrm{I} \text { av. }}=0.71,0.61,0.63 \mathrm{~N} / \mathrm{mm}\right.$, respectively). However, it increased by approximately $63 \%$ for $4.1 \mathrm{~mm}$ $\left(G_{\text {I av. }}=1.16 \mathrm{~N} / \mathrm{mm}\right)$, and it decreased by about $10 \%$ (in comparison with $4.1 \mathrm{~mm}$ ) for the $10.1 \mathrm{~mm}\left(G_{\text {I av. }}=1.04 \mathrm{~N} / \mathrm{mm}\right)$.

In a bulk adhesive specimen, the plastic deformation zone for a growing crack assumes a rounded shape of diameter equal to $2 r_{\mathrm{p}}$, which is given by [6],

$$
2 r_{\mathrm{p}}=\frac{1}{\pi} \frac{E_{\mathrm{a}} \cdot G_{\mathrm{Ic}-\mathrm{a}}}{\sigma_{\mathrm{y}}^{2}} \text { for in-plane stress conditions, }
$$

Table 5

Average value of the exponent $n$ of each representative specimen per bond line thickness.

\begin{tabular}{llllll}
\hline $2 t$ & $0.4 \mathrm{~mm}$ & $1.1 \mathrm{~mm}$ & $2.6 \mathrm{~mm}$ & $4.1 \mathrm{~mm}$ & $10.1 \mathrm{~mm}$ \\
\hline$n$ & 2.2686 & 2.8196 & 2.4876 & 2.1666 & 2.5346 \\
\hline
\end{tabular}




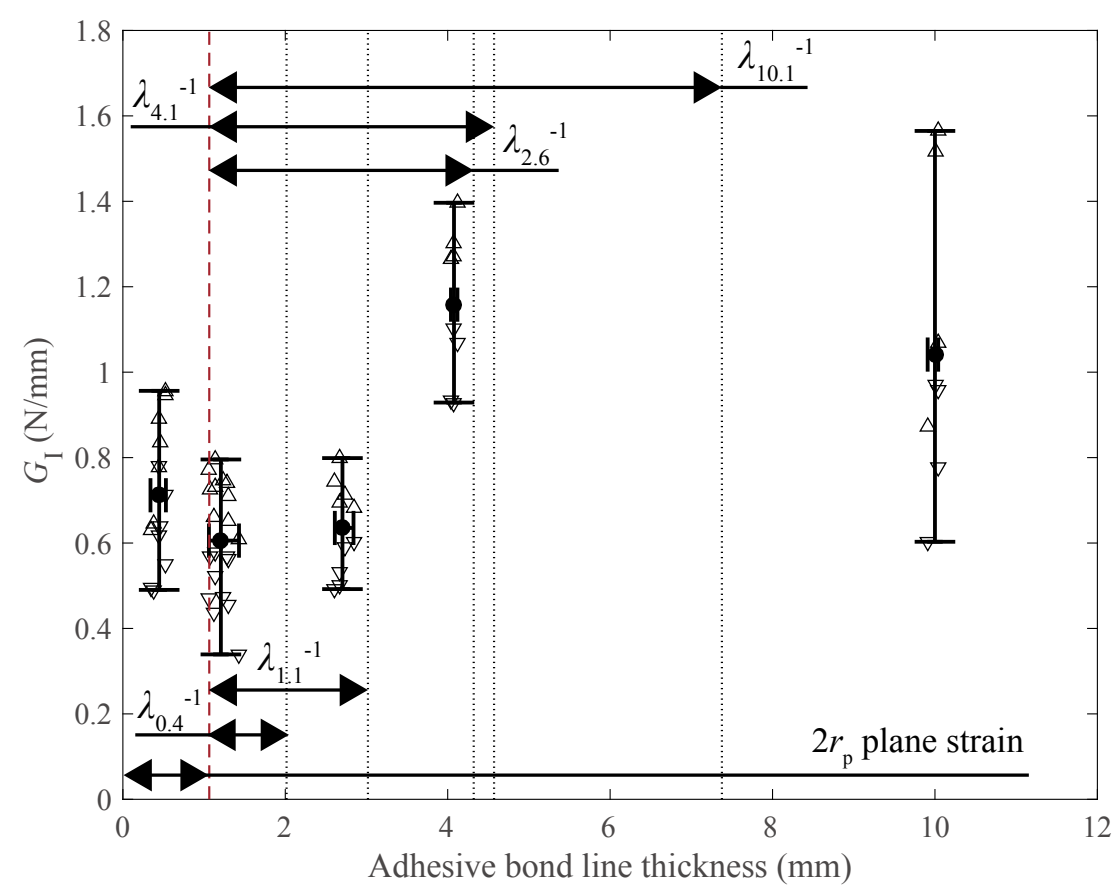

Fig. 11. Adhesive bond line thickness effect on Mode I fracture toughness: P-K model results, considering 3D plane strain conditions. The maximum (" $\Delta$ ") and minimum (" $\nabla$ ") values of $G_{\mathrm{I}}$ of each specimen are plotted against the average thickness of the corresponding bond line. Two error bars are also plotted, giving the range of scatter on the thickness and $G_{\mathrm{I}}$ results of each bond line thickness. The average value of $G_{\mathrm{I}}$ (i.e., "•" symbol) corresponds to the mean of all points (maximum and minimum) plotted for each bond line thickness. The red dashed line gives the limit of $2 r_{\mathrm{p}}$ considering plane strain conditions. The black dashed lines give the limit of $2 r_{\mathrm{p}}+\lambda_{j-\exp }^{-1}$, where $j=0.4,1.1,2.6,4.1,10.1 \mathrm{~mm}$.

$$
2 r_{\mathrm{p}}=\frac{1}{3 \pi} \frac{E_{\mathrm{a}} \cdot G_{\mathrm{Ic}-\mathrm{a}}}{\sigma_{\mathrm{y}}^{2}} \frac{1}{\left(1-\nu_{\mathrm{a}}^{2}\right)} \quad \text { for in-plane strain conditions, }
$$

where $\nu_{\mathrm{a}}$ is the adhesive Poisson's ratio, $G_{\mathrm{Ic}-\mathrm{a}}$ is the critical mode I fracture toughness of the bulk adhesive, and $\sigma_{\mathrm{y}}$ is the yield strength of the adhesive. The stress state near the crack tip varies from plane stress in the edge regions to plane strain in the central regions of the bonded joints. The tensile stress necessary for yielding is higher under the influence of plane strain conditions, leading to a smaller plastic zone, as can be deducted from Eqs. (17) and (18).

The length $2 r_{\mathrm{p}}$ for the epoxy adhesive here studied is presented in Table 6 . The plane stress and plane strain conditions are considered. Moreover, the plane strain plastic zone length, $2 r_{\mathrm{p}}$, is represented by means of a dashed red line in Fig. 11 . For determining $2 r_{\mathrm{p}}$ in Eqs. (17) and (18), a $\sigma_{\mathrm{y}}$ of $16.1 \mathrm{MPa}$ is used (from Table 1). The average value of $G_{\mathrm{I}-\mathrm{P}-\mathrm{K}}$ of $4.1 \mathrm{~mm}$ thick bond line is considered as the critical mode I fracture toughness of the bulk adhesive, $G_{\text {Ic-a }}$. Considering the scenario that the maximum mode I fracture energy for the specimen geometry and materials used in the present study is attained for a bond line thickness of 4.1 mm thick bond line, the bulk adhesive mode I toughness would be smaller as shown by $[6,4]$. Consequently, by considering $G_{\mathrm{I}-\mathrm{P}-\mathrm{K}}$ of $4.1 \mathrm{~mm}$ thick bond line as the critical mode I fracture toughness of the bulk adhesive, $G_{\text {Ic-a }}$, the prediction of $2 r_{\mathrm{p}}$ is overestimated. However, for the purpose of the discussion of the results, the tendency between the length of the analytical plastic zone and the theoretically one would remain the same, as it is described in Section 5.2.

\subsection{Displacement \& stress field ahead the crack tip}

Figs. 12(a), (c) and (e), 13(a) and (c) present the prediction of the transverse displacement in the bonded region, $w_{\text {bon }}$, for all studied bond line thicknesses based on the P-K model. The crack tip is located at $x=0$. The points used for model validation are represented in Fig. 5. These points were selected from the propagation region (after $P_{\max }$ ). The peel stresses profile, $\sigma_{z z}$, in the adhesive layer is shown in Figs. 12(b), (d) and (f), 13(b) and (d). The calculations are based on the displacement field, $w(x)$, determined by the P-K model, Eq. (7),

Table 6

$2 r_{\mathrm{p}}$ - The plastic process zone length, Eqs. (17) and (18).

\begin{tabular}{ccc}
\hline & Plane stress & Plane strain \\
\hline $2 r_{\mathrm{p}}(\mathrm{mm})$ & 2.88 & 1.08 \\
\hline
\end{tabular}




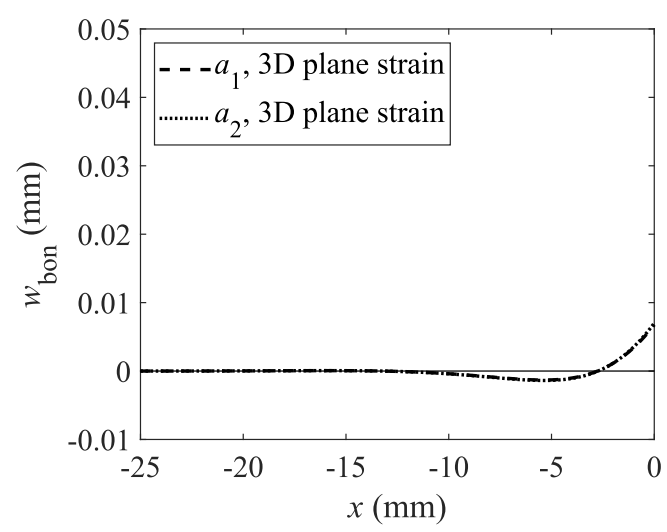

(a) $2 t=0.4 \mathrm{~mm}$ : close-up of $w_{\mathrm{bon}}$.

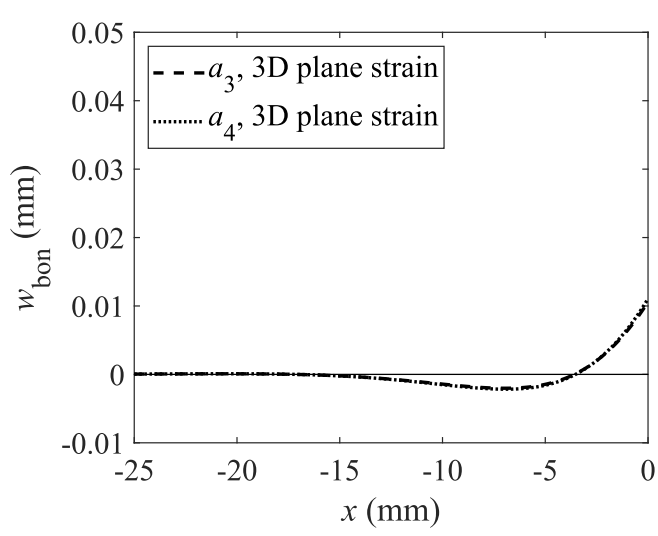

(c) $2 t=1.1 \mathrm{~mm}$ : close-up of $w_{\mathrm{bon}}$.

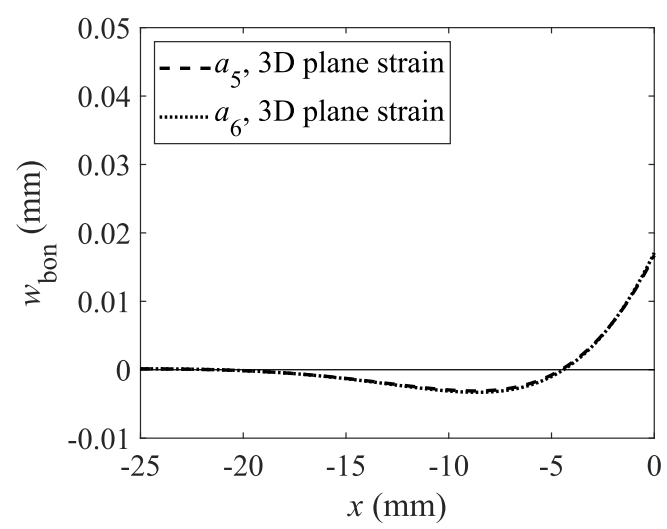

(e) $2 t=2.6 \mathrm{~mm}$ : close-up of $w_{\mathrm{bon}}$.

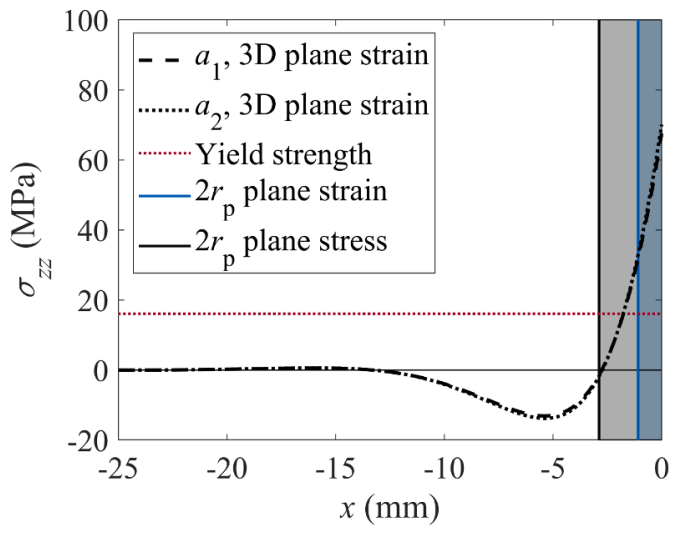

(b) $2 t=0.4 \mathrm{~mm}: \sigma_{z z}$.

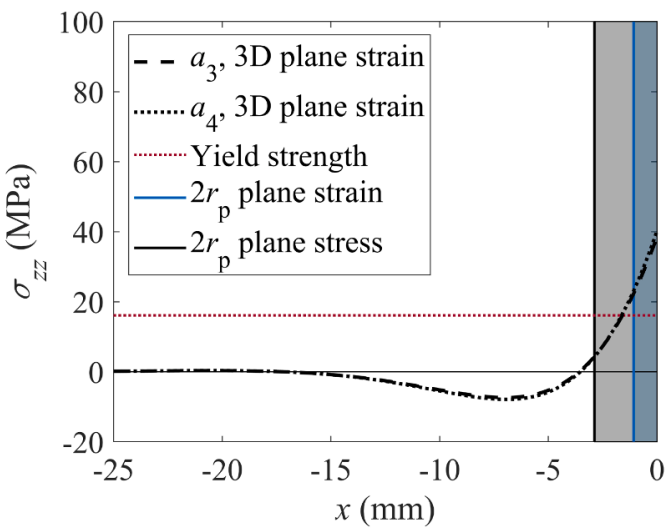

(d) $2 t=1.1 \mathrm{~mm}: \sigma_{z z}$.

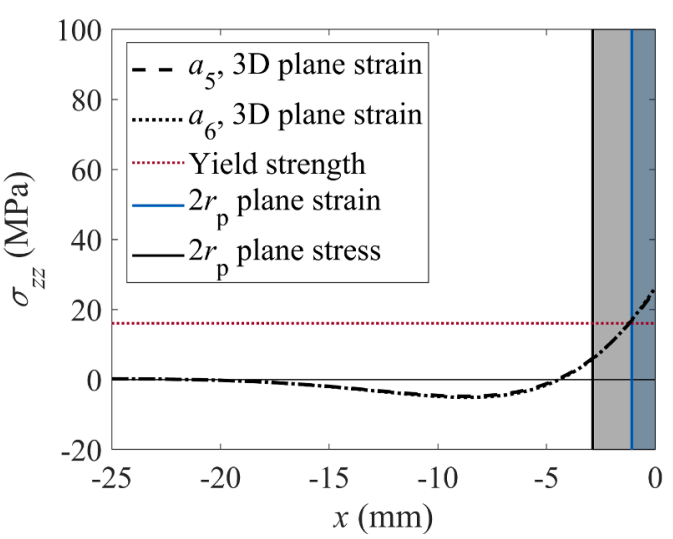

(f) $2 t=2.6 \mathrm{~mm}: \sigma_{z z}$

Fig. 12. Displacement \& stress field ahead of the crack tip based on the P-K model, considering $m_{3}(-\infty \leqslant x \leqslant 0)$. The crack tip is located at $x=0$. Two arbitrary points in the propagation region were selected for each representative specimen: $a_{i}, P_{i}(i=1-6)-$ see Fig. 5 .

$$
\sigma_{z z}=\frac{E_{\mathrm{a}} \cdot w_{i}(x)}{t} \quad-\infty \leqslant x \leqslant 0
$$

where $i=1-10$ and represents the points chosen in the propagation region of the representative specimens. An upper limit from the yield strength of the bulk adhesive, from Table 1, is also plotted in Figs. 12(b), (d) and (f), 13(b) and (d) to define the length of $\lambda^{-1}$, which is the distance over which the positive elastic peel stress is distributed up to the yield strength, $\sigma_{\mathrm{y}}$. In addition, both the plane strain and plane stress plastic zone length are plotted in Figs. 12(b), (d) and (f), 13(b) and (d). The region under peel stresses, $\sigma_{z z}$, 


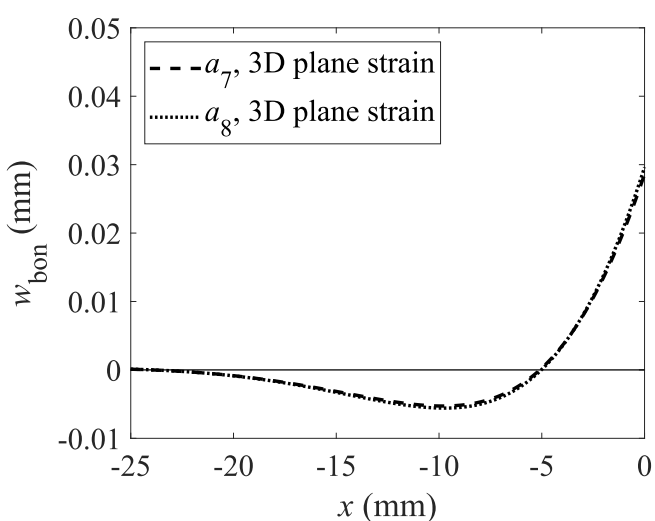

(a) $2 t=4.1 \mathrm{~mm}$ : close-up of $w_{\mathrm{bon}}$.

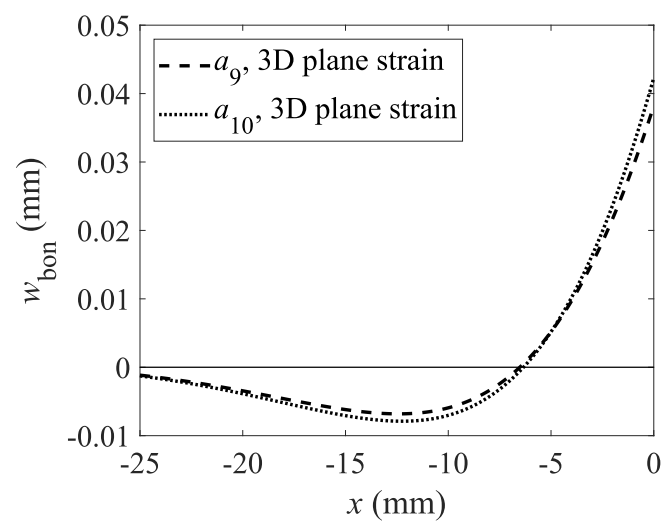

(c) $2 t=10.1 \mathrm{~mm}$ : close-up of $w_{\mathrm{bon}}$.

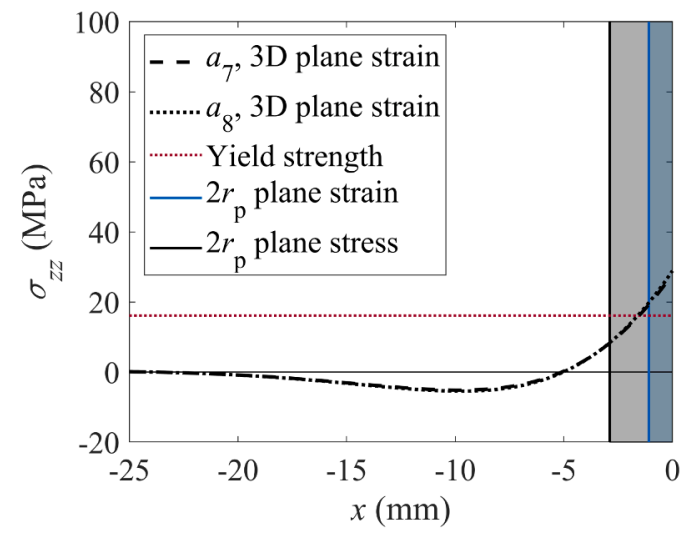

(b) $2 t=4.1 \mathrm{~mm}: \sigma_{z z}$.

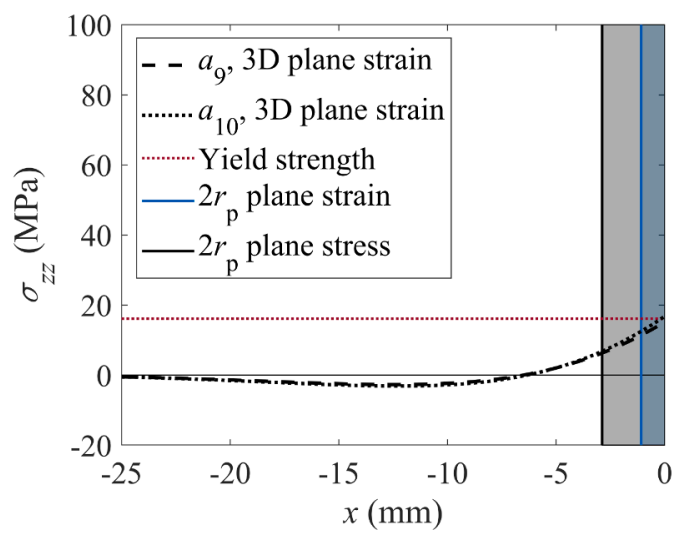

(d) $2 t=10.1 \mathrm{~mm}: \sigma_{z z}$.

Fig. 13. Displacement \& stress field ahead of the crack tip based on the P-K model, considering $m_{3}(-\infty \leqslant x \leqslant 0)$. The crack tip is located at $x=0$. Two arbitrary points in the propagation region were selected for each representative specimen: $a_{i}, P_{i}(i=7-10)-$ see Fig. 5 .

Table 7

$2 w_{\text {unbon }}(x=a)$ : Experimental vs. analytical results, considering $m_{3}$. The reader is referred to Fig. 5 to identify the location of the Point $i$ on the corresponding $P-2 \Delta$ curve.

\begin{tabular}{|c|c|c|c|c|c|c|c|c|c|c|}
\hline \multirow{2}{*}{$\frac{2 t}{\text { Point } i}$} & \multicolumn{2}{|c|}{$0.4(\mathrm{~mm})$} & \multicolumn{2}{|c|}{$1.1(\mathrm{~mm})$} & \multicolumn{2}{|c|}{$2.6(\mathrm{~mm})$} & \multicolumn{2}{|c|}{$4.1(\mathrm{~mm})$} & \multicolumn{2}{|c|}{$10.1(\mathrm{~mm})$} \\
\hline & 1 & 2 & 3 & 4 & 5 & 6 & 7 & 8 & 9 & 10 \\
\hline$P_{i}$ & 285.69 & 238.94 & 256.51 & 191.13 & 284.50 & 191.06 & 363.27 & 306.23 & 313.67 & 249.23 \\
\hline$a_{i}$ & 46.11 & 57.99 & 47.77 & 68.67 & 42.84 & 67.98 & 45.46 & 57.17 & 43.91 & 63.15 \\
\hline $2 \Delta_{i}$ & 2.37 & 3.40 & 2.11 & 3.60 & 2.06 & 4.67 & 2.27 & 3.04 & 2.22 & 3.87 \\
\hline $2 w_{\text {unbon }}\left(x=a_{i}\right)$ & 1.95 & 3.11 & 2.05 & 4.19 & 1.80 & 4.26 & 2.80 & 4.36 & 2.31 & 4.97 \\
\hline \% Error & -18 & -9 & -3 & 16 & -13 & -9 & 23 & 43 & 4 & 28 \\
\hline
\end{tabular}

higher than the adhesive's yield strength, $\sigma_{\mathrm{y}}$, is the so-called plastic zone.

The values of $2 w_{\text {unbon, } i}\left(x=a_{i}\right)$ were compared with the experimental ones, $2 \Delta_{i}$. The results using $m_{3}-3 \mathrm{D}$ plane strain are summarized in Table 7. Reasonable agreement is found between the analytical and the experimental displacements regardless of the adhesive bond line thickness, as shown in Table 7. However, the deviations from the experimental results are higher in the thicker specimens, namely the ones with a bond line thickness of 4.1 and $10.1 \mathrm{~mm}$, as is shown in Table 7. In these specimens, the change of the crack path location along the adhesive layer thickness affects the total displacement, $2 \Delta$, which is not taken into account in the P$\mathrm{K}$ model. The P-K model assumes that the crack is located at the mid-thickness of the adhesive layer. Moreover, in the derivation of the P-K model is assumed that the stiffness of the adhesive layer can be neglected in the unbonded region of the specimen when $\frac{E_{\mathrm{a}}}{E} \leqslant 0.05$ and the adhesive layer is thin. When that is not the case, in order to have more accurate predictions, an effective adherend height, which takes the adhesive's stiffness in consideration, should be implemented [32,37].

The elastic fracture process zone length, $\lambda_{\text {exp }}^{-1}$, was determined from the experimental results (i.e., from the $w_{\text {unbon }}-a$ curve computed using the experimental data $P_{i}, a_{i}$ ). As aforementioned, $\lambda_{\exp }^{-1}$ is defined as the distance over which the positive peel stress is 
Table 8

$\lambda_{\text {exp }}^{-1}$ Experimental results, considering $m_{3}$.

\begin{tabular}{ccccc}
\hline $2 t(\mathrm{~mm})$ & 0.4 & 1.1 & 2.6 & 4.1 \\
\hline$\lambda_{\exp }^{-1}$ & 0.95 & 1.95 & 3.26 & 3.51 \\
\hline
\end{tabular}

distributed up to the yield strength of the bulk adhesive, see Figs. 12(b), (d) and (f), 13(b) and (d). The values of $\lambda_{\text {exp }}^{-1}$ are summarized in Table 8. As expected, the elastic fracture process zone length increases with the adhesive bond line thickness. Concerning the region of $\sigma_{z z}$ in the plastic domain, its length is overestimated by the plane stress plastic zone length (the light grey shaded region length up to $x=0$ in Figs. 12(b), (d) and (f), 13(b) and (d)), which is expected as the plane stress conditions are representative of the edge regions. There is a better agreement between the theoretical (Table 6) and the experimental predictions of the length of the plastic region when considering plane strain conditions (the light blue shaded region length in Figs. 12(b), (d) and (f), 13(b) and (d)). Indeed, the stress state near the crack tip in the central regions of the bonded joints are better represented by the plane strain conditions.

\subsection{Discussion}

According to Kinloch and Shaw findings [6], the specimens with a bond line thickness of $1.1 \mathrm{~mm}$ would be the tougher ones as $2 t \approx 2 r_{\mathrm{p}}$ (plane strain conditions) - see Table 6. Although this is not the case for the adhesive investigated in this study, their theory can still support the overall trend of $G_{\mathrm{I}}$ as a function of the bond line thickness. Moreover, Irwin [18] showed that in a tensile loaded panel, the plastic deformation zone has a circular shape of diameter equal to $2 r_{\mathrm{p}}$. In a bonded joint, the physical constraints of the adherends affect the shape and size of the plastic deformation zone and, consequently, the fracture toughness of the joint. The influence of the adherends on the geometry of this region varies with the bond line thickness and is discussed hereafter.

In the specimens with thin bond lines of $0.4 \mathrm{~mm}$, the effect of the adherends constraint is more pronounced, leading to higher confinement of the crack tip and higher local peel stresses, as shown in Fig. 12(b). The adherends' constraint effect seems to expand the plastic deformation zone as the length of this region is higher than $2 r_{\mathrm{p}}$ (plane strain conditions), resulting in a more elongated deformation zone with an elliptical shape, as reported by Kinloch and Shaw [6] and Wang et al. [21]. By increasing the bond line thickness up to $2.6 \mathrm{~mm}$, the adherends' constraint effect gets smaller, and, consequently, the plastic deformation zone length decreases and it seems to converge to the length of the plane strain $2 r_{\mathrm{p}}$, as can be seen in Fig. 12(f). In the range of bond line thicknesses of 0.4 to $2.6 \mathrm{~mm}$, it would be expected an increase on the average value of $G_{\mathrm{I}}$ as the physical constraint becomes less pronounced for thicker bond lines and, naturally, the deformation zone becomes larger in volume. However, the experimental results show a different trend. Similar average $G_{I}$ values are obtained in the range of 0.4 to $2.6 \mathrm{~mm}$ thick adhesive layer. The high deviations from the average $G_{\mathrm{I}}$ on each of these bond lines affect the final result. Indeed, as shown in Sections 4.1 and 4.2, the joint strength slightly decreased in the specimens with a bond line of 1.1 and $2.6 \mathrm{~mm}$ in comparison with the thinnest ones with a bond line thickness of $0.4 \mathrm{~mm}$. Furthermore, the failure surfaces and crack paths present some differences. In the thinnest specimens, the surfaces are characterized by several peaks (Fig. 7(a)). For the thicker specimens of a bond line of 1.1 and $2.6 \mathrm{~mm}$, the failure surfaces appear smoother and the changes on the crack path plane location might have prevented the full development of the deformation zone, leading in the end to similar results of $G_{I}$. Table 8 shows that $\lambda_{\exp }^{-1}$ increases with the bond line thickness. However, it did not seem to affect the average value of $G_{I}$ in the bond line thicknesses range of $0.4-2.6 \mathrm{~mm}$, which shows that energy dissipation mainly occurs in the plastic deformation zone.

In the specimens with a bond line of $4.1 \mathrm{~mm}$, the adherends' constraining effect is supposed to be even lower due to the total thickness of the bond line. Therefore, the deformation zone should be fully developed, leading to higher energy dissipation before crack propagation, and consequently, to higher $G_{\mathrm{I}}$ values. In fact, there was a rise of approximately $84 \%$ in the average value of $G_{\mathrm{I}}$ from a bond line of $2.6 \mathrm{~mm}$ to a bond line of $4.1 \mathrm{~mm}$. The joint strength was the highest amongst the studied bond line thicknesses, as is shown in Fig. 5(d). According to Kinloch and Shaw [6], the plastic deformation zone for this bond line thickness should have height equal to $2 r_{\mathrm{p}}$ and length longer than $2 r_{\mathrm{p}}$. The results in Fig. 13(b) agree with Kinloch and Shaw theory regarding the increase in the length of the deformation zone. Nevertheless, the P-K model assumes perfectly cohesive crack propagation (i.e., at the mid-thickness of the bond line), which is not representative of the real crack path profile of the $4.1 \mathrm{~mm}$ thick adhesive bond line specimens (see Fig. 7(d)). In fact, the change on the crack plane might have affected the shape, size and direction of the deformation zone, namely in the regions where the crack propagated close to one of the interfaces. Consequently, the real deformation zone length might be slightly different from the estimated by the P-K model. However, despite the real crack path, it seems that the deformation zone could develop more in the specimens with a bond line thickness of $4.1 \mathrm{~mm}$ than in the ones with $2.6 \mathrm{~mm}$ thick adhesive bond line as it is shown by the higher average $G_{I}$ value obtained.

Finally, in the specimens with a bond line of $10.1 \mathrm{~mm}$, the crack grew alternating between the two interfaces (but always within the adhesive layer). Consequently, the propagation occurred most likely under mixed mode conditions, because no geometrical and material symmetries were observed during crack propagation. As a consequence of the crack path location, the deformation zone was physically constrained just in one side (by the adherend), which might have reduced its size, and, subsequently, the mode I fracture toughness. The estimation of $\lambda_{\exp }^{-1}$ and the plastic deformation zone from Fig. 13(d) might not be representative of the experiment due to the crack plane location. As aforementioned, in the P-K model is assumed that the crack is located at the mid-thickness of the bond line. The deeper understanding of possible reasons behind alternating crack path are distinct from the core objective of this paper, 
and hence the interested reader is referred to [40-44] for more details.

Although the same adhesive was used in the present study and on the study of Maloney [4], two different trends of the mode I fracture toughness as a function of the adhesive bond line thickness were obtained. Maloney's results show an increase on the mode I fracture toughness from a bond line thickness of $0.2 \mathrm{~mm}$ up to $1.1 \mathrm{~mm}\left(G_{\text {Ic }}=0.19\right.$ and $G_{\text {Ic }}=0.73 \pm 0.07 \mathrm{~N} / \mathrm{mm}$, respectively). At this thickness, a maximum on the fracture toughness is observed. For thicknesses higher than the optimum, the mode I fracture toughness tends to the bulk adhesive toughness, $G_{\text {Ic }}=0.64 \pm 0.07 \mathrm{~N} / \mathrm{mm}$. The reader should note that Maloney's specimens were cured $16 \mathrm{~h}$ at $60{ }^{\circ} \mathrm{C}$, while the specimens manufactured for the present study were cured $1 \mathrm{~h}$ at $80^{\circ} \mathrm{C}$. By comparison of the experimental stressstrain curves of both cured systems, a more flexible behaviour is found on the system cured at $80{ }^{\circ} \mathrm{C}$ with an average failure strain of about $5 \%$, while the system cured at $60{ }^{\circ} \mathrm{C}$ presents a failure strain of about $3 \%$.

The research done in the past has proved that there is a dependence of the fracture energy of adhesive joints on bonding thickness, regardless of the nature of the adhesives. However, there is no single trend for this dependency. Some studies [3,6,1,4] affirm that the critical mode I fracture energy is directly related to the size of the process zone forming in the adhesive material ahead of the crack tip and its variation with adhesive layer thickness is determined by the constraint effect from the adherends. In the present study, the average mode I fracture toughness, $G_{\text {I av. }}$ presented similar values for the specimens with adhesive bond line thicknesses in the range of $0.4 \mathrm{~mm}$ to $2.6 \mathrm{~mm}$, and it increased by approximately $63 \%$ for the joints of $4.1 \mathrm{~mm}$ thick bond line. Further increase in the thickness of the adhesive layer led to a decrease of about $10 \%$ in $G_{\text {I av. }}$ (in comparison with 4.1 mm thick bond layer). These results show that the increase in bond thickness does not always lead to an increase in the critical fracture energy. The reasons for the trend of these results are attributed to: (a) the crack path, which influences the stress field ahead of the crack tip and, consequently, the size of the deformation zone, and (b) the differences in the fracture surfaces'morphology.

\section{Conclusions}

The effect of the adhesive bond line thickness, varying from 0.4 to $10.1 \mathrm{~mm}$, on the mode I fracture behaviour of steel to steel joints bonded with a structural epoxy adhesive was investigated. This range of bond line thicknesses is relevant for maritime applications, where the efficient production of the superstructures leads to required thicker bonds than for aerospace applications. An experimental test campaign of double cantilever beam (DCB) specimens was carried out in laboratory conditions. Five bond line thicknesses were studied: $0.4,1.1,2.6,4.1$ and $10.1 \mathrm{~mm}$.

Analytical predictions of the experimental load-displacement curves were performed based on the Simple Beam Theory (SBT), the Compliance Calibration Method (CCM) and the Penado-Kanninen (P-K) model. The P-K model was used to determine the mode I

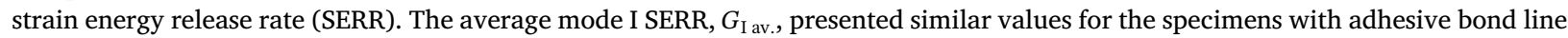
thicknesses of $0.4,1.1$ and $2.6 \mathrm{~mm}\left(G_{\text {Iav. }}=0.71,0.61,0.63 \mathrm{~N} / \mathrm{mm}\right.$, respectively). However, it increased by approximately $63 \%$ for $4.1 \mathrm{~mm}\left(G_{\mathrm{I} \text { av. }}=1.16 \mathrm{~N} / \mathrm{mm}\right)$, and decreased about $10 \%$ (in comparison with $4.1 \mathrm{~mm}$ ) for the $10.1 \mathrm{~mm}\left(G_{\mathrm{I} \text { av. }}=1.04 \mathrm{~N} / \mathrm{mm}\right)$. The trend

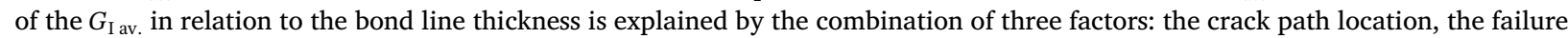
surfaces features and the stress field ahead of the crack tip.

In all tested specimens, the crack has propagated cohesively (regardless of the bond line thickness). However, the crack showed a tendency to propagate with an alternating trajectory (i.e., the crack grew along an alternating path along the bond line thickness). This behaviour affects the stress field ahead of the crack tip and, consequently, the extent of the deformation zone ahead of it (i.e., crack propagation in the mid-thickness of the adhesive layer allows the full development of the process zone, while propagation in a plane more remote from the specimen mid-plane restricts the development of this zone). Among all tested bond line thicknesses, it seems that the alternating crack path pattern affected the least the thinnest bond line of 0.4 mm, leading to similar values of the average $G_{\mathrm{I}}$ in the range of $0.4-2.6 \mathrm{~mm}$. Moreover, the average joint strength was higher and the failure surfaces were rougher in the bond line of $0.4 \mathrm{~mm}$ than in the specimens with bond lines of 1.1 and $2.6 \mathrm{~mm}$. Although the alternating (wavy) pattern on the crack path was also present in the specimens with an adhesive layer thickness of $4.1 \mathrm{~mm}$, it is thought that the deformation zone could

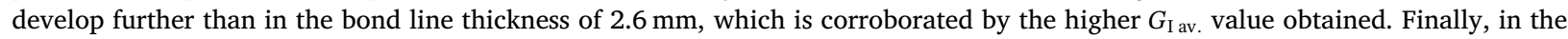
thickest specimens $(\approx 10 \mathrm{~mm})$, the crack onset moved towards the steel-epoxy interface due to geometry singularity. The crack grew alternating between the two interfaces. As a consequence of the crack path location, the deformation zone was physically constrained just on one side, which might have decreased its size, and, subsequently, the mode I fracture toughness.

The mode I fracture toughness-bond line thickness trend presented in this study shows that the increase in bond thickness does not always lead to a rise in the critical fracture energy. The reasons for this trend are attributed to: (a) the crack path, which influences the stress field ahead of the crack tip and, consequently, the size of the deformation zone, and (b) the differences in the fracture surfaces'morphology.

\section{DOI}

The data required to reproduce these findings are available at: https://doi.org/10.4121/uuid:b3fe805b-3833-42a9-bcd8de39c2211ca7

\section{Acknowledgements}

This research was carried out under project number S32.6.14552a - Durabond in the framework of the Partnership Program of the Materials innovation institute M2i (www.m2i.nl) and the Technology Foundation TTW (www.stw.nl), which is part of the 
Netherlands Organization for Scientific Research (www.nwo.nl). The Durabond project is linked to a Joint Industry Project (JIP) set up by TNO, separately funded by Topconsortium voor Kennis en Innovatie (TKI) HighTech Systemen \& Materialen (HTSM).

\section{Appendix A. Supplementary material}

Supplementary data associated with this article can be found, in the online version, at https://doi.org/10.1016/j.engfracmech. 2019.106607.

\section{References}

[1] Hunston DL, Kinloch AJ, Wang SS. Micromechanics of fracture in structural adhesive bonds. J Adhes 1989;28:103-14. https://doi.org/10.1080/ 00218468908030877. URL: http://www.tandfonline.com/doi/abs/10.1080/00218468908030877.

[2] Ouezdou MB, Chudnovsky A. Stress and energy analysis of toughness measurement for adhesive bonds. Eng Fract Mech 1988;29:253-61.

[3] Bascom WD, Cottington RL, Jones RL, Peyser P. The fracture of epoxy- and elastomer-modified epoxy polymers in bulk and as adhesives. J Appl Polym Sci $1975 ; 19: 2545-62$.

[4] Maloney KJ. Micro-architected adhesive joints [Ph.D. thesis]. University of Cambridge; 2016.

[5] Marzi S, Biel A, Stigh U. On experimental methods to investigate the effect of layer thickness on the fracture behavior of adhesively bonded joints. Int J Adhes Adhes 2011;31:840-50. https://doi.org/10.1016/j.ijadhadh.2011.08.004.

[6] Kinloch AJ, Shaw SJ. The fracture resistance of a toughened epoxy adhesive. J Adhes 1981;12:59-77. https://doi.org/10.1080/00218468108071189.

[7] Carlberger T, Stigh U. Influence of layer thickness on cohesive properties of an epoxy-based adhesive-an experimental study. J Adhes 2010;86:814-33. https:// doi.org/10.1080/00218464.2010.498718.

[8] Lee D-B, Ikeda T, Miyazaki N, Choi N-S. Effect of Bond Thickness on the Fracture Toughness of Adhesive Joints. Journal of Engineering Materials and Technology 2004;126:14-8. https://doi.org/10.1115/1.1631433. URL: http://materialstechnology.asmedigitalcollection.asme.org/article.aspx?articleid=1427090.

[9] Ranade SR, Guan Y, Ohanehi DC, Dillard JG, Batra RC, Dillard DA. A tapered bondline thickness double cantilever beam (DCB) specimen geometry for combinatorial fracture studies of adhesive bonds. Int J Adhes Adhes 2014;55:155-60. https://doi.org/10.1016/j.ijadhadh.2014.08.006.

[10] Cooper V, Ivankovic A, Karac A, McAuliffe D, Murphy N. Effects of bond gap thickness on the fracture of nano-toughened epoxy adhesive joints. Polymer 2012;53(24):5540-53. https://doi.org/10.1016/j.polymer.2012.09.049.

[11] Pardoen T, Ferracin T, Landis CM, Delannay F. Constraint effects in adhesive joint fracture. J Mech Phys Solids 2005;53(9):1951-83. https://doi.org/10.1016/j. jmps.2005.04.009.

[12] Daghyani HR, Ye L, Mai YW. Mode-I Fracture Behaviour of Adhesive Joints. Part II. Stress Analysis and Constraint Parameters. J Adhes 1995;53(3-4):163-72. https://doi.org/10.1080/00218469508009936.

[13] Daghyani HR, Ye L, Mai YW. Mode-I Fracture Behaviour of Adhesive Joints. Part I. Relationship Between Fracture Energy and Bond Thickness. J Adhes 1995;53(3-4):149-62. https://doi.org/10.1080/00218469508009935.

[14] Banea MD, Da Silva LF, Campilho RD. The effect of adhesive thickness on the mechanical behavior of a structural polyurethane adhesive. J Adhes 2014;91:331-46. https://doi.org/10.1080/00218464.2014.903802.

[15] Cabello M, Zurbitu J, Renart J, Turon A, Martínez F. A general analytical model based on elastic foundation beam theory for adhesively bonded DCB joints either with flexible or rigid adhesives. Int J Solids Struct 2016;94-95:21-34. https://doi.org/10.1016/j.ijsolstr.2016.05.011.

[16] Biel A, Stigh U. Cohesive zone modelling of nucleation, growth and coalesce of cavities. Int J Fract 2017;204:159-74. https://doi.org/10.1007/s10704-0160168-9.

[17] de Moura MFSF, Campilho RDSG, Gonçalves JPM. Crack equivalent concept applied to the fracture characterization of bonded joints under pure mode I loading. Compos Sci Technol 2008;68:2224-30. https://doi.org/10.1016/j.compscitech.2008.04.003.

[18] Maiti SK. Linear elastic fracture mechanics. Fracture mechanics: fundamentals and applications 1st ed.Cambridge University Press; 2015. p. 6-64. https://doi. org/10.1007/978-0-387-68188-7_2. Ch. 2 1408.4413v1. URL: http://link.springer.com/10.1007/978-0-387-68188-7_2.

[19] Geiss PL, Schumann M. Investigation of the mechanical properties of interphases in adhesively bonded epoxy-aluminum joints by localized micro extensometry. J Adhes 2012;88:941-55.

[20] Possart W, Krüger JK, Wehlack C, Müller U, Petersen C, Bactavatchalou R, et al. Formation and structure of epoxy network interphases at the contact to native metal surfaces. Comptes Rendus Chimie 2006;9:60-79. https://doi.org/10.1016/j.crci.2005.04.009.

[21] Wang SS, Mandell JF, McGarry FJ. An analysis of the crack tip stress field in DCB adhesive fracture specimens. Int J Fract 1978;14:39-58. https://doi.org/10. 1007/BF00032383.

[22] ISO 527:2012, Plastics - Determination of tensile properties; 2012.

[23] Li G, Wang X, Li A, Wang W, Zheng L. Fabrication and adhesive properties of thin organosilane films coated on low carbon steel substrates. Surf Coat Technol 2007;201:9571-8. https://doi.org/10.1016/j.surfcoat.2007.04.032.

[24] ASTM D 5528/ D 5528-13. Standard test method for mode I interlaminar fracture toughness of unidirectional fiber-reinforced polymer matrix composites; 2013, doi:https://doi.org/10.1520/D5528-13.2. URL: http://scholar.google.com/scholar?hl=en\&btnG=Search\&q=intitle:Standard + Test + Method + for + Mode + I + Interlaminar + Fracture + Toughness + of + Unidirectional + Fiber-Reinforced + Polymer + Matrix + Composites\# 2 .

[25] Heide-Jorgensen S, Budzik MK. Crack growth along heterogeneous interface during the DCB experiment. Int J Solids Struct 2017;120:1339-51. https://doi.org/ 10.1016/j.ijsolstr.2017.05.013.

[26] Berry JP. Determination of fracture energies by the cleavage technique. J Appl Phys 1963;34:62-8.

[27] Budzik M, Jumel J, Shanahan ME. Adhesive compliance effect in mode I separation: profilometry approach. Int J Adhes Adhes 2011;31:135-45. https://doi.org/ 10.1016/j.ijadhadh.2010.11.012.

[28] Budzik M, Jumel J, Imielińska KI, Shanahan ME. Effect of adhesive compliance in the assessment of soft adhesives with the wedge test. J Adhes Sci Technol 2011;25:131-49. https://doi.org/10.1163/016942410X501133.

[29] Kanninen MF. An augmented double cantilever beam model for studying crack propagation and arrest. Int J Fract 1973;9:83-92.

[30] Lefebvre DR, Dillard DA, Brinson HF. The development of a modified double-cantilever-beam specimen for measuring the fracture energy of rubber to metal bonds. Exp Mech 1988;28(1):38-44. https://doi.org/10.1007/BF02328994.

[31] Ouezdou MB, Chudnovsky A, Moet A. Re-evaluation of adhesive fracture energy. J Adhes 1988;25(3):169-83. https://doi.org/10.1080/00218468808071260.

[32] Penado FE. A closed form solution for the energy release rate of the double cantilever beam specimen with an adhesive layer. J Compos Mater 1993;27:383-407. https://doi.org/10.1177/002199839302700403. URL: http://journals.sagepub.com/doi/10.1177/002199839302700403.

[33] Chow CL, Woo CW, Sykes JL. On the determination and application of COD to epoxy-bonded aluminium joints. J Strain Anal 1979;14:37-42.

[34] Krenk S. Energy release rate of symmetric adhesive joints. Eng Fract Mech 1992;43:549-59.

[35] Jumel J, Budzik MK, Shanahan ME. Beam on elastic foundation with anticlastic curvature: application to analysis of mode I fracture tests. Eng Fract Mech 2011;78:3253-69. https://doi.org/10.1016/j.engfracmech.2011.09.014.

[36] Dillard DA, Mukherjee B, Karnal P, Batra RC, Frechette J. A review of Winkler's foundation and its profound influence on adhesion and soft matter applications. Soft Matter 2018;14(19):3669-83. https://doi.org/10.1039/c7sm02062g.

[37] Salem NB, Budzik MK, Jumel J, Shanahan ME, Lavelle F. Investigation of the crack front process zone in the double cantilever beam test with backface strain monitoring technique. Eng Fract Mech 2013;98:272-83. https://doi.org/10.1016/j.engfracmech.2012.09.028.

[38] Akisanya AR, Fleck NA. Analysis of a wavy crack in sandwich specimens. Int J Fract 1992;55:29-45. https://doi.org/10.1007/BF00018031.

[39] Akisanya AR, Meng CS. Initiation of fracture at the interface corner of bi-material joints. J Mech Phys Solids 2003;51:27-46. https://doi.org/10.1016/S00225096(02)00076-5.

[40] Banks-Sills L, Ashkenazi D. A note on fracture criteria for interface fracture. Int J Fract 2000;103(2):177-88. https://doi.org/10.1023/A:1007612613338. 
[41] Fleck NA, Hutchinson JW, Zhigang S. Crack path selection in a brittle adhesive layer. Int J Solids Struct 1991;27(13):1683-703. https://doi.org/10.1016/00207683(91)90069-R.

[42] Chen B, Dillard DA. Numerical analysis of directionally unstable crack propagation in adhesively bonded joints. Int J Solids Struct 2001;38(38-39):6907-24. https://doi.org/10.1016/S0020-7683(01)00006-3.

[43] Evans AG, Dalgleish BJ, He M, Hutchinson JW. On crack path selection and the interface fracture energy in bimaterial systems. Acta Metall 1989;37(12):3249-54. https://doi.org/10.1016/0001-6160(89)90197-1.

[44] Chen B, Dillard DA. The effect of the T-stress on crack path selection in adhesively bonded joints. Int J Adhes Adhes 2001;21(5):357-68. https://doi.org/10. 1016/S0143-7496(01)00011-2. 